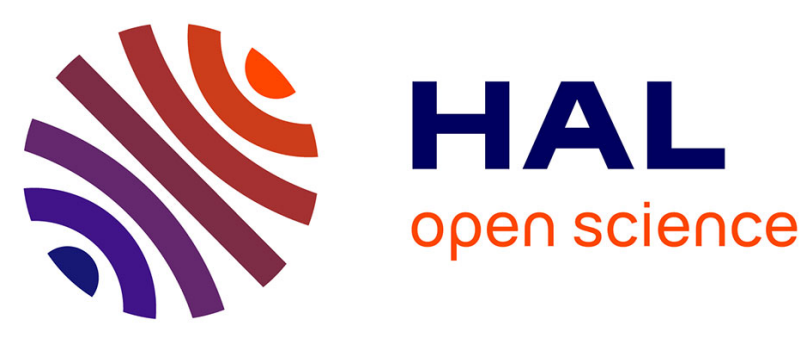

\title{
Management of post-mining large-scale ground failures: blast swarms field experiment for calibration of permanent microseismic early-warning systems
}

Isabelle Contrucci, Emmanuelle Klein, Pascal Bigarre, Armand Lizeur, Anthony Lomax, Mustapha Bennani

\section{To cite this version:}

Isabelle Contrucci, Emmanuelle Klein, Pascal Bigarre, Armand Lizeur, Anthony Lomax, et al.. Management of post-mining large-scale ground failures: blast swarms field experiment for calibration of permanent microseismic early-warning systems. Pure and Applied Geophysics, 2010, 167 (1-2), pp.43-62. 10.1007/s00024-009-0005-4 . ineris-00961742

HAL Id: ineris-00961742

https://hal-ineris.archives-ouvertes.fr/ineris-00961742

Submitted on 20 Mar 2014

HAL is a multi-disciplinary open access archive for the deposit and dissemination of scientific research documents, whether they are published or not. The documents may come from teaching and research institutions in France or abroad, or from public or private research centers.
L'archive ouverte pluridisciplinaire HAL, est destinée au dépôt et à la diffusion de documents scientifiques de niveau recherche, publiés ou non, émanant des établissements d'enseignement et de recherche français ou étrangers, des laboratoires publics ou privés. 


\title{
Management of post-mining large-scale ground failures: blast swarms field experiment for calibration of permanent microseismic early-warning systems
}

\author{
I. Contrucci (1), E. Klein (1), P. Bigarré (1), A. Lizeur (1), A. Lomax (2) and M. Bennani (1)
}

(1) Institut National de l'Environnement Industriel et des Risques (INERIS), Ecole des Mines de Nancy, Parc de Saurupt, CS 14324, 54042, NANCY Cedex, France. E-mail: Isabelle.Contrucci@ineris.fr, Emmanuelle.Klein@ineris.fr, Pascal.Bigarre@ineris.fr.

(2) ALomax Scientific, 161 Allée du Micocoulier, 06370 Mouans-Sartoux, France. E-mail: anthony@alomax.net.

ACCEPTED May 09, PAGEOPH.

Abstract - In France, decades of coal and iron ore mining have left extensive underground cavities beneath or in the vicinity of urban areas. This poses an environmental challenge for society. To ensure post-mining risk management and public safety, wherever remediation is not possible, numerous real-time microseismic monitoring systems are being installed. The objective is to detect remote rock mass fracturing processes, precursory events and acceleration phases for appropriate and timely action. Although no consistent collapse has occurred in any of the monitored areas yet, single 3D probes record many microseismic events of very low amplitude which create difficulties in the quantitative data analysis. The development of specific quantitative processing has therefore become a major issue in our research work. For that purpose, a field experiment was carried out on six of the instrumented sites. It consisted of sequences of small blasts in mine pillars which were accurately controlled in terms of the location, orientation and energy of the explosive source. The data analysis was used to calibrate parameters (velocity model, 3D sensor orientation, etc.) for reliable $3 \mathrm{D}$ localization and to develop an empirical law to estimate the source energy from the sensor energy. This work now enables us to analyze real microseismic events with a much better level of accuracy and to obtain enough information and confidence to discuss these data in terms of site 
stability.

Keywords: mine collapse, risk management, microseismicity, early warning system, 3D location, velocity model

\section{Introduction}

In the Lorraine area of Eastern France, decades of iron-ore mining from 1850 to 1997 have left vast underground cavities beneath or in the vicinity of urban areas. At present, these residual voids are estimated at 500 million $\mathrm{m}^{3}$ and represent $40,000 \mathrm{~km}$ of underground galleries. This now poses a societal and environmental challenge: major collapses took place in the 1990s in the southern part of the Lorraine iron-ore basin in the cities of Auboué, Moutiers and Roncourt. These events occurred a few months after the mine closure and the progressive rise of the water level in the underground working caused by the halt of the de-watering system (Didier, 2008).

These large scale ground failure events prompted a request from both the government and local authorities for a management strategy to be set up to prevent and control post-mining risks. A methodology was thus established in order to assess hazard zones and rank them according to their vulnerability due to human surface infrastructure and activity. The high risk zones are secured either by reducing the hazard or by using in situ monitoring. As it is rarely possible to deal with the hazard itself, public safety is often ensured through real-time microseismic monitoring systems that are installed in the zones in question.

For that purpose, INERIS deployed an innovative microseismic monitoring platform that was tested and validated during the Terres Rouges experiment in 1997 (Senfaute et al., 2000; Couffin et al., 2003; Bennani et al., 2004). This platform is designed to detect rock mass fracturing that first affect the old mine workings before reaching the overburden and finally the surface. More than thirty real-time 
microseismic monitoring networks have been installed since 1998 in the Lorraine iron-ore basin by the CENARIS $^{1}$ at INERIS. These networks have been designed following a methodology based on the geological context, the dimensions of the zone being monitored, the hazards involved and the technical installation and maintenance constraints due to urbanization. The most vulnerable buildings are instrumented with geotechnical sensors linked to the microseismic system to ensure a smart triggering scheme (Klein et al., 2008).

Although no major collapse has occurred in any of these areas yet, small microseismic events are often recorded. These events, with low amplitudes $\left(\sim 10^{-6} \mathrm{~mm} / \mathrm{s}\right)$ and negative magnitudes raise real quantitative analysis problems, especially in terms of localisation and spatial-temporal breakdown which are essential in understanding instability mechanisms (Driad et al., 2005). Although publications exist on the microseismic monitoring of working mines (e.g. Senfaute et al., 1997; Driad et al., 2005; Li et al., 2007) or on the long-term analysis of microseismicity in abandoned mines (Miller et al., 1989; Ogasawara et al., 2002), none of them describe the applied methods, tools or data management strategy.

This lack of methods, combined with the flooding of the Nord iron-ore basin scheduled to start at the end of 2005, motivated a large-scale field experiment to help to calibrate data processing parameters and to estimate microseismic source parameters. This experiment was performed in six instrumented zones where mine workings were still accessible. It consisted of numerous blasts sequences to ensure the high sensitivity of the monitoring devices and to calibrate some of the fundamental numeric data processing procedures using accurately-controlled input data.

This article describes the sequence of the 2005 calibration experiment and the methods adopted to confirm the high sensitivity of sensors based on blast data. Details will then be given on the

\footnotetext{
${ }^{1}$ French National Monitoring Centre for Ground and Underground Risks created by INERIS
} 
calibration procedure for the 3D localisation tool and the determination of its main input parameters, especially the velocity model. An empirical law to calculate the source energy from the hypocentral distance, in the geological context of the Lorraine iron-ore basin, is also estimated. Finally, the transfer of these results to the operational point of view will be discussed.

\section{Geological context of the Lorraine iron-ore basin}

The Lorraine iron-ore basin, located on the eastern boundary of the Paris basin, extends for approximately one hundred kilometres from North to South and twenty to thirty kilometres from East to West. The Pont-à-Mousson anticline splits the region into two distinctive zones: the BrieyLongwy-Thionville basin to the North and the Nancy basin to the South. The Lorraine iron-ore basin formations are marine in origin and were subject to very little deformation after their deposit. The basin is nevertheless cut by major faults of several kilometres long oriented NE-SW. The ironore series and its cover show a dip of several degrees towards the South-West, except near the major fractures where the local dip can be as much as $10^{\circ}$, as for example at the Audun-le-Tiche fault.

The iron-ore series belongs to the Toarcian and Aalenian stages. The marly-carbonated cover belongs to the Bajocian. Overall, the various geological formations found in the basin are as follows (Bennani \& Homand, 2004): (1) the Doncourt oolitic Limestones; (2) the Jaumont oolitic Limestones; (3) the upper and lower Polypiers Limestones; (4) the Haut-Pont Limestones; (5) the Ottange Limestones; (6) the Charennes Marls; (7) the iron-ore formation. The geometry, thickness and extent of these series can vary laterally rapidly. Not all these formations are found in all the experimental sites. For example, Doncourt Oolitic Limestones are only found in the west of the iron-ore basin.

The iron-ore formation can be considered as alternating between marls and ores. It is between 0 and $65 \mathrm{~m}$ thick, $40 \mathrm{~m}$ on average (Montagne et al., 1992). Nine ore-bearing layers have been counted in the entire basin (Maubeuge, 1955), named using colours. Usually two to three layers were exploited 
with the rooms and pillars operating method below urban areas, with pillar extraction outside urban areas. A total of 3.1 billion tonnes of iron ore were extracted, i.e. about 1.2 billion $\mathrm{m}^{3}$ over a surface area of $1700 \mathrm{~km}^{2}$.

\section{Field experiment design}

\subsection{Experimental sites}

The field experiment took place between October 2005 and May 2006 in the cities of Audun-le-

Tiche, Fontoy, Tressange, Nondkeil, Ottange and Moutiers (Figure 1). These municipalities were already equipped with permanent microseismic monitoring networks; the underground workings were accessible during the experiments on all sites except Moutiers. Each monitoring network includes one or more microseismic stations. Each station consists of three probes equipped with miniature broadband geophones and cemented into boreholes as follows: one 1D probe on the surface, one $1 \mathrm{D}$ probe about $15 \mathrm{~m}$ below the surface and one $3 \mathrm{D}$ probe about $50 \mathrm{~m}$ below the surface. The orientation of the 3D probe was measured at the installation into the borehole. The local coordinate system used is the Lambert 1 . The stations are connected to an acquisition unit, which automatically detects, records and transfers data to the monitoring central site of INERIS at Nancy, in quasi real-time via, a secure high bandwidth link.

\subsection{Experimental procedure}

Apart from the Moutiers site, where the blasts were made from a vertical borehole, the experiments involved small dynamite blasts in mine pillars at depths of between 50 and $250 \mathrm{~m}$ depending on the site. TITADYNE AG 30 dynamite was the explosive used, packed in a cartridge $50 \mathrm{~mm}$ in diameter placed in $76 \mathrm{~mm}$-diameter boreholes $5 \mathrm{~m}$ deep. The explosive charges were chosen to produce signals with usable signal-to-noise ratio yet avoiding sensor saturation. Thus, the sources were 
dynamite charges between 0.5 to $12 \mathrm{~kg}$, depending on the experimental site and its configuration. The blast positions were chosen considering both the best "blast-to-station" distance coverage and the best angular coverage when mine accesses so permitted. Various blast configurations were also used on each site to test the resolution of the numerical processing tools, including 3D location and source parameters calculations. The first combination, a so-called "single blast", involved one single blast in a borehole (Figure 3-a). The second combination, a so-called "orientation blast", comprised two blasts of equivalent charge in the same pillar placed in perpendicular boreholes (Figure 3-b). Lastly, a combination of orientation and single blasts - "multiplet blast" - involved four blasts using different charges in the same pillar, including one in a borehole perpendicular to the other three (Figure 3-c). When possible, fixed X and Y coordinate blasts were also reproduced in other exploited levels to test the robustness of the localisation at depth.

The "multiplet blast" configuration was performed to record "multiplets" a term which refers, in classic seismology, to a group of seismic events showing the following characteristics (Geller and Mueller, 1980; Poupinet et al. 1984; Lees 1998; Slunga et al., 1995; Moriya et al. 2006; Gibowicz, 2006): similar wave form; different time origin; considered as the result of the relaxation of constrain of a single fracture or fault, similar source mechanisms; close location; different magnitude. The recorded data might indeed be used to test the capabilities of "relative" location algorithms compared to "absolute" and classical seismic location algorithms. The relative approach is supposed to improve the location of one order of magnitude compared to absolute location (Rubin et al., 1999; Waldhauser and Ellsworth, 2000; Schaff et al., 2002).

Seventy blasts were performed in total, producing over 1270 seismograms (Table 1). The recorded seismograms show a frequency spectrum of between 30 and $500 \mathrm{~Hz}$ for hypocentral distances of less than $300 \mathrm{~m}$ (Figure 4). This frequency range was found to "fit" correctly the frequency range 
observed from a previous experiment during which caving induced events were recorded (Senfaute $e t$ al., 2000).

\begin{tabular}{|c|c|c|c|c|c|c|}
\hline \multirow{2}{*}{ Site } & $\begin{array}{c}\text { Number of } \\
\text { microseimic } \\
\text { stations }\end{array}$ & $\begin{array}{c}\text { Number of } \\
\text { blasts }\end{array}$ & \multicolumn{2}{|c|}{$\begin{array}{c}\text { "Blast-to-station" } \\
\text { distance }\end{array}$} & $\begin{array}{c}\text { Mass of } \\
\text { explosives }\end{array}$ & $\begin{array}{c}\text { Number of } \\
\text { seismograms }\end{array}$ \\
\cline { 4 - 6 } Fontoy & 2 & 13 & 100 & 900 & $\begin{array}{c}3.0 \mathrm{~kg}-12.0 \\
\mathrm{~kg}\end{array}$ & 130 \\
\hline Tressange & 4 & 13 & 170 & 1000 & $\begin{array}{c}2.0 \mathrm{~kg}-5.0 \\
\mathrm{~kg}\end{array}$ & 260 \\
\hline $\begin{array}{c}\text { Audun- } \\
\text { le-Tiche }\end{array}$ & 3 & 11 & 80 & 1050 & $\begin{array}{c}2.0 \mathrm{~kg}-9.0 \\
\mathrm{~kg}\end{array}$ & 165 \\
\hline Nondkeil & 4 & 10 & 110 & 370 & $\begin{array}{c}0.5 \mathrm{~kg}-2.0 \\
\mathrm{~kg}\end{array}$ & 140 \\
\hline Ottange & 5 & 18 & 90 & 1300 & $\begin{array}{c}2.0 \mathrm{~kg}-10.0 \\
\mathrm{~kg}\end{array}$ & 468 \\
\hline Moutiers & 4 & 5 & 80 & 480 & $\begin{array}{c}1.0 \mathrm{~kg}-5.0 \\
\mathrm{~kg}\end{array}$ & 115 \\
\hline TOTAL & $\mathbf{2 2}$ & $\mathbf{7 0}$ & $\mathbf{8 0}$ & $\mathbf{1 3 0 0}$ & $\begin{array}{c}\mathbf{0 . 5} \mathbf{~ k g}-\mathbf{1 2 . 0} \\
\mathbf{~ k g}\end{array}$ & $\mathbf{1 2 7 8}$ \\
\hline
\end{tabular}

Table 1: table summarising the number of blasts, blast to station distance, charges and signals recorded per site.

\section{Data processing: example of the Tressange site}

Microseismic data processing started with a systematic analysis of all the seismograms in terms of amplitude, signal-to-noise ratio and sensor energy to assess data quality. All the recorded 3D seismograms were then analysed for polarisation to check consistency between measured incident angles and expected values at the 3D probes, thereby ensuring the correct azimuthal orientation of these probes (\$4.2). The geological formation velocities for the overburden were then estimated from the inversion of both P-wave arrival times and measured polarisation angles, taking into account the multilayered geology of the site. The blasts were re-localised based on the velocity model thus calculated (\$ 4.3.3). Lastly, an empirical law for calculating source energy was determined based on 
the sensor distance and energy $(\$ 4.4)$. This approach is illustrated below with the Tressange check blast data (Figure 2), except for the source energy calculation where all the sites are considered.

\subsection{Data quality}

A systematic analysis of all seismograms per site and microseismic station in terms of amplitude and energy was undertaken in order to assess data quality. This analysis demonstrated the excellent sensitivity of the monitoring systems, able to detect $1 \mathrm{~kg}$ blasts at a distance of up to $300 \mathrm{~m}$. For analysis, only signals with signal to noise ratio higher than 10 were considered. Note that in such a "near-field" experiment, where sources generate mainly compressional stress waves, only P-waves are observed; the S-wave energy is not observed on the recorded data. This limitation will be discussed here below.

\subsection{Polarisation analysis}

Analysing polarisation by wave rotation is used to calculate incident angles (azimuth and dip) of the ray path at the three-component probe from a 3D seismogram. The estimated direction of the incident ray path provides important information that can be used along with the measured $\mathrm{P}$ and $\mathrm{S}$ arrival times to constrain efficiently the solution for source location. This approach, which assumes prior knowledge of the orientation of the $3 \mathrm{D}$ probes, is of most importance when localisation relies on only a few microseismic stations (Magotra et al., 1987; Abdul-Wahed et al., 2001; Volker and Roth, 2003). In the current study, the azimuths of the 3D probes were measured with a releasable compass during grouting into the vertical boreholes. As the blast positions are known, the orientation measurements can be checked easily by examining the expected and measured directions by a polarisation analysis of each $3 \mathrm{D}$ seismogram. The expected direction is calculated by assuming an isotropic homogeneous medium between the blast and the $3 \mathrm{D}$ probe, i.e. assuming a straight ray path between these two points. This hypothesis is reasonable regarding the short "blast-to-probe" 
distance and the relative homogeneity of the encountered geology. Note that in such sub-horizontal media, the calculated azimuth does not depend on the velocity model. On the contrary, the measured dip of the ray path may depend significantly on the gradient velocity of the stratified overburden when contrasting velocities between layers are considered.

On the Tressange site, the expected azimuths at the 3D probes at the Nationale and Liberté stations match the measured azimuths; the mean error, assessed using quality factors such as rectilinarity and planarity factors (Samson, 1983), is $\sim 5^{\circ}$. However, for the Gerbault and Jardins probes, a systematic mean misfit of $50^{\circ}$ and $-200^{\circ}$ respectively is noted between the expected and calculated azimuths (Figure 5). These systematic misfits are caused uncontrolled rotation of 3D probes during grout injection while the orientation device is released and pulled out. These misfits have been corrected at each station, thus providing true probe orientation. Note that blast 08 , located underneath the Liberté station, has a major azimuthal misfit (Figure 5) because of the inconsistent solution for ray path with a dip close to $90^{\circ}$. Note also that a bias between expected and measured dip values is observed for all stations: the bias is less than $5^{\circ}$ for the Liberté, Jardins and Nationale stations (Figure 6 ), it is $\sim 9^{\circ}$ for the Gerbault station (Figure 6). It is most likely due to straight ray paths assumption.

\section{3. $3 D$ localisation of the blasts}

This stage consists in performing blast re-localisation to test the performance of the localisation algorithm thanks to the known blast positions (\$4.3.4). Firstly, it is necessary to build up a velocity model based on the site's geological structure (\$4.3.1). P-wave velocities for each layer are calculated taking account all available input data, i.e. positions of the blasts, direct P-wave arrival times and dips measured at the 3D probes (see $\$ 4.2$ ). Note that $\mathrm{S}$ wave arrival times were not available and measured azimuths are of no interest in the velocity calculation. For this purpose, a velocity model optimization program has been developed (4.3.3). 


\subsubsection{Geology of the Tressange site}

The Tressange site is located on the Eastern part of a fault system extending from Mont-Bonvillers to Ottange, oriented SW-NE to SSW-NNE. Note the presence of the Ottange fault, orientated SSWNNE, at Tressange (Figure 2). The fault throw is several metres and the East block is the collapsed block with layers dipping regionally in the order of 3\% westwards or WSW (Lopes, 2002). As shown in Figure 2, the Nationale and Jardins stations are situated in the West fault block whereas the other stations are located in the East block. The Ferdinand mine shaft (Table 2), which is located to the west of the Gerbault station, in the East block, shows that the geological structure comprises six main facies (Table 2). The geological structure adopted for Tressange is based on these different characteristics.

\begin{tabular}{|c|c|c|}
\hline \multicolumn{3}{|c|}{$\begin{array}{c}\text { Coordinates (Lambert 2 extended) } \\
\text { FERDINAND SHAFT }\end{array}$} \\
$\mathbf{X}=864456.9$ Y $=2495763.8$ and Z = 347.51 $\mathbf{~}$ \\
\hline Geological facies: & $\begin{array}{c}\text { Depth of the layer } \\
\text { roof }(\mathbf{m})\end{array}$ & $\begin{array}{c}\text { Layer thickness } \\
\text { (m) }\end{array}$ \\
\hline Overburden & - & - \\
\hline Jaumont Limestones & 0 & 14 \\
\hline Polypiers Limestones & 14 & 85 \\
\hline $\begin{array}{c}\text { Haut-Pont/Ottange } \\
\text { Limestones }\end{array}$ & 99 & 54 \\
\hline Charennes Marls & 153 & 28.4 \\
\hline Iron-ore formation & 181.4 & - \\
\hline
\end{tabular}

Table 2: Geological facies found at the Ferdinand shaft on the Tressange site.

\subsubsection{Construction of an inversion type velocity model}

SYTMISvel software was specially developed for automatically adjusting a velocity model to a determined geological structure comprised of inclined parallel layers with known thicknesses (Contrucci et al., 2008). This model is build up by inversion, using the arrival times of the $\mathrm{P}$ and/or S waves and the polarisation angles. Velocities are calculated with or without knowledge of the absolute initial time (T0) of the recorded seismograms. 
SYTMISvel program explores numerous velocity models, which have been generated randomly, according to a Monte-Carlo type algorithm (Lomax and Snieder, 1995): the applicability of these models is assessed according to the differences between calculated and observed data with respect to their uncertainty. The models achieving the most effective minimisation of the difference between calculated and observed data are selected, if the velocities calculated in the individual layers are consistent with the local geology.

The differences between calculated and observed data are minimised by using either the least-square misfit function (L2-norm) or the Equal Differential Time misfit function (EDT-norm; Pinsky et al., 2008; Lomax, 2005).

For the L2-norm, the function to be minimised is expressed as:

$$
p d f_{L S L 2}=k \exp \left\{-\sum_{o b s_{i}} \frac{\operatorname{Wobs}_{i}(x)-\operatorname{Tcalc}_{i}(x)_{-}^{\overline{2}}}{\sigma_{i^{2}}}-\sum_{o b s_{j}} \frac{\operatorname{bobs}_{j}(x)-\operatorname{\theta calc}_{j}(x)^{\overline{2}}}{\sigma_{j^{2}}}\right\}
$$

with: $\mathrm{x}$, the position of the source; Tobs $_{\mathrm{i}}$ and $\mathrm{Tcalc}_{\mathrm{i}}$, the arrival times observed and calculated from observation; $\theta \mathrm{obs}_{\mathrm{i}}$ and $\theta$ calc $_{\mathrm{i}}$ are the polarisation angles observed and calculated; $\sigma_{\mathrm{i}}$ and $\sigma_{\mathrm{j}}$ are the uncertainties; $\mathrm{k}$ a normalisation constant.

For the EDT-norm, the function to be minimised is expressed as:

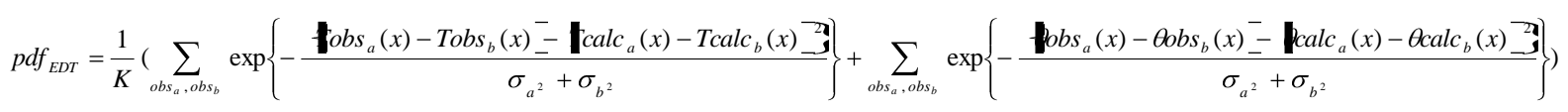

with: Tobs ${ }_{a}$ and Tcalc $c_{b}$, the arrival times for observations a and b; Tcalc and Tcalc $_{b}$, the calculated travelling times; $\theta \mathrm{obs}_{\mathrm{a}}$ and $\theta \mathrm{obs}_{\mathrm{b}}$ are the polarisation angles observed for observations a and b; $\theta \mathrm{calc}_{\mathrm{a}}$ and $\theta$ calc $_{\mathrm{b}}$ are the polarisation angles calculated; $\sigma_{\mathrm{a}}$ and $\sigma_{\mathrm{b}}$ are the respective uncertainties; $\mathrm{K}$, a normalisation constant. 
This minimization process uses a global approach since the travel times are non-linearly related to the velocities in the individual layers. The program input comprises mainly the following information: 1) the method used to randomly generate sets of velocity models either the traditional Monte-Carlo method which defines randomly the entire velocity model or the "Metropolis" MonteCarlo method in which each model tested in a Metropolis loop, is close to the last model selected (a random walk similar to the simulated annealing method); 2) the geological structure and the observed data, i.e., the number of geological layers and the velocity range for P and S-waves; the thicknesses of the layers and their possible dips; the positions of the microseismic stations and blast points; the arrival times of the $\mathrm{P}$ and/or $\mathrm{S}$ waves for each blast and each of the $1 \mathrm{D}$ and $3 \mathrm{D}$ probes, as well as associated picking errors and the incidence angles observed for each blast at each 3D probe and associated errors. The program output comprises principally the difference between calculated and observed arrival times and incidence angles for each blast and each of the considered probes and the probability of occurrence of each velocity model.

\subsubsection{Velocity model for the Tressange site}

The thicknesses of the model's layers are based on the geological structure observed on the log of the Ferdinand Shaft (Table 2). Several tests were carried out in order to determine the best velocity model with the layer thicknesses indicated in Table 2. The minimisation between calculated and observed values was achieved by using the L2-norm. Regardless of the configuration of the data used for the inversion, significant misfits were indeed obtained when the EDT-norm was employed. This norm does not seem to be adapted to the geometry of the problem and the dimensions of the geological structure studied: the double difference of the arrival times and angles affects the information contained in our data, and thus generates aberrant velocity values.

The best velocity model is determined in two main steps. The first steps consists in inverting all of the data, i.e. all of P-wave arrival times and incidence angles of all blasts. It allows identifying the data 
with large misfit between calculated and observed values (Figure 7-a-b-c). Figure 7-a shows that time misfits higher than $0.04 \mathrm{~s}$ are observed for blast 1 on Gerbault station, and blasts 1,4 and 14 on Liberté station. The high misfit observed for blast 1 on Gerbault station is probably related to a local heterogeneity in the vicinity of the blast point. This hypothesis seems reasonable since the hypocentral distance is, in that case, short. On the contrary, the high time misfits observed for blasts 1, 4 and 14 on Liberté station are probably due to the large hypocentral distances. These high distances can induce significant signal attenuation, leading to high picking errors. These misfits and errors can also be emphasized by anisotropic wave propagation. Figure 7-b shows three significant azimuth misfits. For blast 8 , at Liberté station, the misfit is due to the fact that the blast is located directly below the Liberté station. Indeed, there exists an infinity of azimuth solutions for a dip close to $90^{\circ}$. For blasts 4 and 14, the azimuth misfits observed respectively at Gerbault and Nationale stations, are difficult to explain since the hypocentral distances are short in both cases. These misfits are however lower than 10\%. They can be neglected since they do not depend on the velocity model. Regarding the dip (Figure 7-c), the greatest misfits are observed for large hypocentral distances, relatively large error in dip for near-horizontal rays in the assumed, constant velocity layered model. As a general rule, the highest misfits, in terms of both polarisation angles and P-arrival times, are observed for blasts performed on the network border. This is probably due to signal attenuation with distance. Also, the boundary ray paths cross geological sequences that are not intersected by other ray paths: the information collected from the boundary ray paths is not crosschecked thus creating high misfits. In other words, this first stage demonstrates that the velocity model has to be calculated with high signal to noise input data. Thus, the second step in the velocity model calculation was carried out by eliminating the "aberrant" errors or high misfits (Figure 8) associated with blasts 1, 4 and 14 . 


\begin{tabular}{|c|c|c|c|c|c|}
\hline \multicolumn{6}{|c|}{ Step 1: all of the data } \\
\hline Formation & $\begin{array}{c}\text { Jaumont } \\
\text { Limestones }\end{array}$ & $\begin{array}{c}\text { Polypiers } \\
\text { Limestones }\end{array}$ & $\begin{array}{c}\text { Haut Pont/ } \\
\text { Ottange } \\
\text { Limestones }\end{array}$ & $\begin{array}{c}\text { Charennes } \\
\text { Marls }\end{array}$ & $\begin{array}{c}\text { Iron-Ore } \\
\text { Formation } \\
\end{array}$ \\
\hline Velocity [m/s] & 5530 & 4820 & 4790 & 3235 & 3215 \\
\hline $\begin{array}{l}\text { Standard } \\
\text { Deviation }[\mathrm{m} / \mathrm{s}]\end{array}$ & 430 & 215 & 1280 & 1435 & 1510 \\
\hline \multicolumn{6}{|c|}{ Step 2: without blasts 1,4 and 14} \\
\hline Velocity $[\mathrm{m} / \mathrm{s}]$ & 2340 & 3375 & 3855 & 3190 & 3190 \\
\hline $\begin{array}{l}\text { Standard } \\
\text { Deviation }[\mathrm{m} / \mathrm{s}]\end{array}$ & 600 & 165 & 920 & 970 & 305 \\
\hline
\end{tabular}

Table 3 : best P-wave velocity model obtained by inversion in steps 1 and 2 .

The step 2 model significantly reduces misfits which exist between calculated and measured values for $\mathrm{P}$ wave arrival times as well as for the polarisation angles of the incident ray (Figure 8). Thus, time misfits vary in a maximum range of $\pm 0.02 \mathrm{~s}$ instead of $0.07 \mathrm{~s}$ after the first step inversion.

The velocities obtained by inversion, for each layer, are indicated in Table 3. The results show that removing aberrant input data considerably reduces the standard deviations, except for Jaumont Limestones which layer is clearly not constrained enough by the input data. Figure 9, which presents the distribution of velocities for each layer, gives additional details on these results. The velocity peak of the Polypiers Limestones layer shows that this layer is very well constrained. For the other layers, the peaks are less well-defined (Figure 9), and thus associated errors are greater (Table 3).

These calculated velocities can also be compared with velocity measurements made in laboratory by Homand and Dagallier (2004). These measurements give an accurate idea of expected velocities in the formations in question, and, the contrast between layers. They show that P-wave velocities vary between 2710 and $4215 \mathrm{~m} / \mathrm{s}$ for the Polypiers Limestones, between 3900 and $5375 \mathrm{~m} / \mathrm{s}$ for the Ottange/Haut-Pont Limestones, between 1965 and 2680 m/s for the Charennes Marls and between 3270 and $3450 \mathrm{~m} / \mathrm{s}$ for the iron-ore formation. These values are consistent with those obtained in this study. Note that the step 2 velocity model shall be selected for re-locating the blasts. 


\subsubsection{D localisation algorithm}

The localisation module implemented in SYTMISauto software used in this study, is based on the combination of the microseismic wave arrival times as well as the polarisation angles, in order to determine the hypocenter with the maximum likelihood. Indeed, the integration of polarisation angles enables to locate an event with few probes, i.e. one $3 \mathrm{D}$ probe and one $1 \mathrm{D}$ probe if only $\mathrm{P}$ waves are detected or a single 3D probe if $\mathrm{P}$ and $\mathrm{S}$ waves are recorded (Magotra et al. 1987; AbdulWahed et al., 2001; Volker and Roth, 2003). The implemented localisation algorithm is based on a probabilistic approach to solve the inverse problem (Tarantola and Valette, 1982). It consists in maximising the probability density function $(p d f)$ of the hypocenter at a given point using EDT or L2 norm. This is done by minimizing the misfit between measured and calculated values, i.e. between observed and calculated arrival times, as well as between observed and calculated polarisation angles. The hypocenter with the maximum likelihood is determined by using the Oct-Tree non-linear method (Lomax and Curtis, 2001), based on a successive division of space into cells depending on the value of the probability calculated for each cell. This approach is used to completely solve the inverse problem and thus provides a representation of the overall $p d f$ of the localisation. The most probable hypocentre corresponds to the $p d f$ maximum. The drawback of this method is that the calculation can take a long time because the entire solution space is explored for each iteration. To limit time calculations, this method can be combined with the linear C.H.E.A.P method (Tarantola and Valette, 1982) based on the determination of a local maximum by gradient calculation, that is to

say of the maximum $p d f$ in the relevant cell. For each event, the $p d f$, as well as the corresponding reliability ellipse at $68 \%$, is calculated.

\subsubsection{Localisation parameters}

Calibration blasts are re-located on the Tressange site with the global Oct-Tree method to avoid the 
restrictions of the linear C.H.E.A.P method described above. The grid size was set as $10 \mathrm{~m}$ minimum and $50 \mathrm{~m}$ maximum. In order to optimise the calculation time, the grid space was limited in a $1500 \mathrm{~m}$ * $1500 \mathrm{~m} * 500 \mathrm{~m}$ cubic space following X Y Z directions. As for the velocity model calculation, localisation processing is run based on the L2-norm, since the EDT-norm did not seem to be adapted to the dimensions of the studied geological structure. Although it seems appropriate for locating regional or worldwide earthquakes by accounting for actual picking errors (Pinsky et al. 2008 ; Lomax, 2005), the EDT-norm generates aberrant localisation solutions in the current study.

The velocity model employed is from SYTMISvel software (\$ 4.3.3). To partially take into account uncertainties related to the velocity model determined previously by inversion, a constant error with value of $\pm 0.002 \mathrm{~s}$ is introduced on all travel times, which corresponds to an error of $\pm 70 \mathrm{~m} / \mathrm{s}$ for a stress wave travelling at $3500 \mathrm{~m} / \mathrm{s}$ over a distance of $350 \mathrm{~m}$. Errors on the incidence angles are assessed at $\pm 10^{\circ}$ which seems reasonable according to Figure 8; manual picking error is set at \pm $0.005 \mathrm{~s}$.

\subsubsection{D localisation results}

Several re-localisation tests were carried out on the 13 blasts related to the site of Tressange. Firstly, only P-wave arrival times were used; secondly, the polarisation angles (azimuths and dips) were added. The results of these tests are summarised in Table 4 and Figure 10. When only P wave arrival times are considered, the mean misfit between the true and calculated positions of the blasts is $260 \mathrm{~m}$ with significant errors in the $\mathrm{Z}$ direction, i.e. depth (210 $\mathrm{m}$ on average). When P-wave arrival times and polarisation angles are taken into account in the localisation, the mean misfit between actual positions and calculated positions is reduced to $70 \mathrm{~m}$ (Table 4). There is a misfit of $48 \mathrm{~m}$ in the X$\mathrm{Y}$ plane and of $47 \mathrm{~m}$ in the $\mathrm{Z}$ direction (Table 4). The localisation quality is improved in nearly every case, except for blast 08 located directly below the Liberty station. In this specific case, the azimuth 
measurement has little meaning as it is determined with a very significant error, which affects localisation quality. On the other hand, blasts $09,10,11$ and 12 located in the centre of the network are located correctly with an error of about $55 \mathrm{~m}$ on average. For blasts $01,04,13$ and 14, located outside the network, signal to noise ratio of the signals recorded on the distant stations is too low for clearly for accurate picking of the first arrivals. The localisation of these blasts, with only two or three stations, is greatly improved with the polarisation angles (Table 4 and Figure 10).

More generally, when only the arrival time is considered, the $p d f$ reveals a North West - South East orientation, related to the geometry of the network. The $p d f$ is far more constrained when polarisation angles are taken into account (Table 4). However, both the input data and the precision of the 3D localisation algorithm remains insufficient for the data recorded with multiplet-type configuration (blasts 9, 10, 11 and 12). It would certainly be useful to use relative localisation methods (Poupinet et al. 1984; Slunga et al., 1995; Abdul-Wahed et al., 2006) to gain precision while re-localizing this kind of data. 


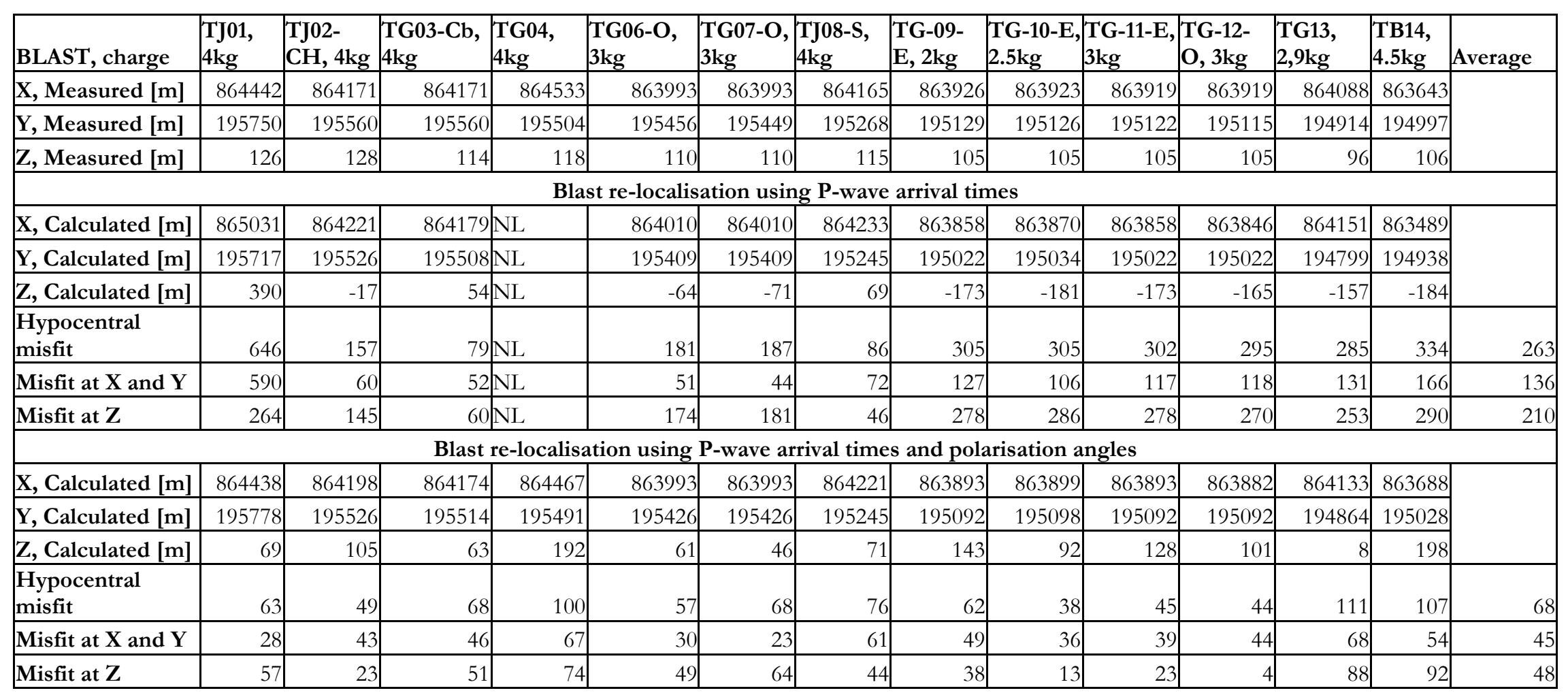

Table 4: Summary of the true and re-calculated positions of microseismic blasts, hypocentral misfits in the $\mathrm{X}-\mathrm{Y}$ plane and depth ( $\mathrm{Z}$ direction), and associated average values. 


\subsection{Seismic energy at the source}

The seismic energy at the source is a key parameter for characterising the intensity of a seismic rupture. It is however necessary to assess the geometrical and anelastic attenuations of the rock mass and the response of the instrumental channel (Urbancic et al. 1993; Boatwright et al., 2002; Yamada et al. 2007) in order to obtain a correct estimate of this energy. Although it is easy to correct the recorded signal of the geometrical attenuation, it is more difficult to perform other corrections without making numerous assumptions. In conventional seismology, the calculation procedures used for characterising the source often involve a double-couple mechanism since fault shearing mechanisms usually generate earthquakes (Brune, 1970; Madriaga, 1976). Based on this approach, the magnitudes of the earthquakes can be assessed, thus allowing the determination of the source energy (Aki and Richards, 1980). However, these techniques cannot be applied directly for assessing the source energy of a micro-seismic event occurring in a mine. Source mechanisms, different from the double-couple, are expected, for instance, traction, implosion or explosion (Gibowicz et al., 1991; McGarr, 1992; Trifu and Shumila 2002; Finck et al., 2003; Sileny and Milev, 2006).

Analyses are currently being conducted to determine and quantify the different corrections to be taken into account in the calculation of the source energy in the context of this study. Therefore, this paper only includes a description of the work concerning the empirical estimation of the source energy from calibration blasts. This approach appears to be a good first order solution since the blasting charges and their positions are known. An empirical relationship between the seismic energy recorded by the sensors and the seismic source energy according to the distance has been defined as follows (Tastet et al., 2007):

$$
E c p t=K \cdot \operatorname{Esrc}^{\gamma} \cdot D^{-\beta}(1)
$$

with Esrc: source energy linked to the explosive charge (J), see equation (2); Ecpt. energy recorded by 
the sensor and calculated from seismograms $(\mathrm{J})$; $D$ : hypocentral distance based on straight ray path assumption (m); K: constant $\left(\mathrm{J}^{1-\gamma} \mathrm{m}^{\beta}\right)$. Note that in such a formulation (1), unknowns are $\mathrm{K}$, $\beta$ and $\gamma$, where $\beta$ quantifies both geometrical and anelastic attenuations and $\gamma$ dissipation and nonlinear source size effects.

The seismic source energy depending on the blasting charge can be expressed as follows:

$$
\text { Esrc }=Q \cdot \text { Etotal } \cdot r(2)
$$

with: $\mathrm{E}_{\text {src }}$, seismic source energy $(\mathrm{J})$; $\mathrm{Q}$, source blasting charge $(\mathrm{kg}) ; \mathrm{E}_{\text {total }}$, total energy released by a blasting charge of $1 \mathrm{~kg}$ depending on explosive used; r, ratio set empirically at 0.6.

The value of the total energy released $\left(\mathrm{E}_{\text {total }}\right)$ by a blasting charge of $1 \mathrm{~kg}$ depends on the blasting agent being used. In this case, it is TITADYN AG 30 which is packaged in cartridges of $50 \mathrm{~mm}$ and $38 \mathrm{~cm}$ in length. As these calibration blasts have been carried out in boreholes (confined space) i.e. in a "blocked blast" configuration, the maximum detonation velocity of $6,000 \mathrm{~m} / \mathrm{s}$ has most probably been reached as well as the maximum energy of $4.2 .10^{6} \mathrm{~J}$ for $1 \mathrm{~kg}$ of blasting charge. This energy includes two terms: the first represents the shock energy and the second the gas energy. Only the shock energy can significantly impact the wave transmission in the rock and contribute to the seismic energy radiated into the rock mass with an insignificant participation of detonation gas. Thus, coefficient $r$ with a value of 0.6 has been applied to the total energy in order to account for this phenomenon. Equation 1 leads to the following expression:

$$
\operatorname{Esrc}^{*}=\left(\frac{E c p t}{K \times D^{-\beta}}\right)^{1 / \gamma} \text { (3) }
$$

where Esrc*: estimated source energy (J); K, $\beta$ and $\gamma$ coefficients are determined, from equation 1, for each experimental site. First, $\beta$ is determined for a given series of blasts of constant source energy Esrc, defined by the blast charge. 
Figure 11 illustrates the correct determination of $\left[K \cdot \operatorname{Esrc}^{\gamma}\right]$ (considered here as a constant with the blast charge) and power law $\beta$.

Secondly, once $\beta$ has been determined, $\mathrm{K}$ and $\gamma$ coefficients are determined to fit all data for the studied site. Eventually, the robustness of the empirical law (2) is evaluated from the standard misfit between estimated Esrc* and the true values of Esrc. The results give a mean error of $\sim 50 \%$, which is very acceptable when one considers all cumulated assumptions. The empirical laws obtained for each site are presented in Table 5.

\begin{tabular}{|c|c|}
\hline Site & Empirical Source energy Law \\
\hline Audun-le-Tiche & $\mathrm{E}_{\mathrm{src}}{ }^{*}=11 \cdot \mathrm{D}^{3.2} \cdot \mathrm{E}_{\mathrm{cpt}}^{0.6}$ \\
\hline Fontoy & $\mathrm{E}_{\mathrm{src}} *=1.2 \cdot \mathrm{D}^{4} \cdot \mathrm{E}_{\mathrm{cpt}}{ }^{0.8}$ \\
\hline Tressange & $\mathrm{E}_{\mathrm{src}}{ }^{*}=5.2 \cdot \mathrm{D}^{3.2} \cdot \mathrm{E}_{\mathrm{cpt}}^{0.5}$ \\
\hline Moutiers Gorcy & $\mathrm{E}_{\mathrm{src}}{ }^{*}=1303 \cdot \mathrm{D}^{2.3} \cdot \mathrm{E}_{\mathrm{cpt}}^{0.5}$ \\
\hline Ottange & $\mathrm{E}_{\mathrm{src}} * 230 . \mathrm{D}^{2.6} \cdot \mathrm{E}_{\mathrm{cpt}}^{0.5}$ \\
\hline All sites & $\mathbf{E}_{\mathrm{src}} *=\mathbf{8 . 6} \cdot \mathbf{D}^{3.4} \cdot \mathbf{E}_{\mathrm{cpt}}{ }^{0.6}$ \\
\hline
\end{tabular}

Table 5 : Source energy estimation laws from sensor energy for each experimental site.

For each studied site, the dependency of the seismic source energy on the energy recorded by a sensor reveals a good homogeneity with $\gamma^{-1}$ values close to 0.5 except for the Fontoy site where this value is equal to 0.8 (Table 5). This value illustrates the significant attenuation observed on this site where it was necessary to perform blasts of up to $12 \mathrm{~kg}$. The dependency of the source energy on the hypocentral distance reveals relatively homogeneous exponents between 2.3 and 4 . The relative homogeneity observed on sites, which are relatively distant from each other, illustrates the geological homogeneity of the Lorraine iron-basin (Figure 11-a) and contributes to the definition of a source energy estimation law common to all sites. In order to develop this law, the same approach employed for a single site has been adopted (Table 5).

This approach, although empirical, can be used for estimating the source energy of the study sites from the measured sensor energy and the position of the event. However, these relationships are 
valid only for P-waves as the blasts have not generated other types of waves. The influence on these empirical relationships of energy related to $\mathrm{S}$ waves, which could be generated by underground failure, must still be assessed. The empirical approach developed here, may however be used to estimate the seismic source energy of real microseismic events on a relative local scale for fast and accurate classification of different events from a unique swarm.

\section{Summary of results and discussion}

The experiment conducted allowed the recording of more than 1200 high quality seismograms, confirming the ability of the microseismic systems deployed to detect signals caused by blasts of $1 \mathrm{~kg}$ of explosives at a distance of more than $300 \mathrm{~m}$. The data signal to noise ratio quality, along with the polarisation analysis allowed the orientation of $3 \mathrm{D}$ probes to be checked and corrected, when necessary, with an accuracy close to $\pm 1^{\circ}$. For the Tressange site, two $3 \mathrm{D}$ probes over four probes presented a systematic error. These probes no doubt rotated in the borehole. On the whole, this experiment allowed the orientations of 7 out of the $223 \mathrm{D}$ probes in question to be corrected and brought about a change in the installation protocol of the probes. These are now installed with a centring system, with extra pressure contacts, limiting any accidental rotation.

As already mentioned, accurate knowledge of the 3D sensors orientation is crucial in the processing and analysis of microseismic data. Together with the arrival times measured at the sensors, through the inversion process, angles allow a realistic velocity model, in relation to the site's geology, to be calculated. However, for the Tressange site it was shown that the calculation of the velocity model depends on good knowledge of the geological structure of the studied site. It depends as well on a precise analysis of parameters to eliminate any abnormal data. The use of an appropriate norm to minimize any differences between the observed and calculated data is also important. In the current study, the L2-norm is far more accurate than the EDT standard, for both velocity model calculation 
and blast re-location.

Calculations of azimuth and dip of the incident rays at the $3 \mathrm{D}$ probes is easy and accurate. Once these angles included in the 3D location algorithm, the accuracy of the absolute location hypocenters increases significantly. For the Tressange site, the average location error is $260 \mathrm{~m}$ when only the arrival times are used and this is reduced to $70 \mathrm{~m}$ when the polarisation angles are also included. This accuracy is sufficient compared to a monitored area of several hectares. This improvement is valid for almost all the blasts, with the exception of blasts located right below stations where the azimuth error is significant. The accuracy of the 3D absolute location algorithm obtained remains insufficient to take advantage of the data recorded in multiplet configurations.

An empirical law providing a relationship between the energy at the source, the energy measured at the sensor and the hypocentral distance was defined for each experimental site. The good homogeneity of these laws reflects the uniformity of the geology at the scale of the Lorraine iron-ore basin. An empirical law, valid throughout the iron-ore field, was estimated. These empirical energy laws are valid for P-waves only, since the blasts did not generate $\mathrm{S}$ waves. The influence of any $\mathrm{S}$ waves, which may be generated by natural failures, should thus be further evaluated. At this stage, the ability to estimate the source energy of a real microseismic event and compare it to blasts test gives already a good order of magnitude.

\section{Conclusion}

The microseismic calibration blasts carried out in the Lorraine iron-ore field form a reference database consisting of 1200 high-quality seismograms. This unique database allows the validation of the tools developed for microseismic analysis and calibration of the microseismic characteristics of each experimental sites. Step-by-step analysis of those data enabled us to: (1) calculate P-wave velocity models of each site and characterize some geophysical properties of the main geological strata ; (2) optimize and validate the 3D localization tool; (3) construct empirical source energy and 
wave propagation laws for the different but geologically similar experimental sites including comparison tests. In the future, we will perform additional research to further characterize the seismic source mechanism. This work will also take into account the relative location method to take advantage of the various blast configurations implemented in this experiment. The results already achieved and the work in progress, should allow the characterisation of post-mining instabilities and their early warning systems in order to enhance decision making.

\section{Acknowledgements}

Special thanks to the French Ministry of Economy, Finance and Industry for the financial support. We fully acknowledge M. E. Rovinalti (former mine manager from ARBED company), M. A. Marnet (DRIRE Lorraine), M. J-P. Josien (former director from GEODERIS) both for authorizations and helpful contribution to the field experiment.

Our thanks also go to the ARBED and ARCELOR companies for the technical support and human resources used during the experiment. We thank the two anonymous reviewers for their suggestions that significantly helped to improve this paper. We do not forget Kathe Hooks (School of Mines of Nancy) for fully re-read this paper.

\section{References}

Abdul-Wahed, M.K., Senfaute, G., Piguet, J.P., Source location estimation using single station threecomponent seismic data, Rock Mechanics - A Challenge for Society: Proceedings of the ISRM Regional Symposium (Eurock 2001, Espoo, Finland, 4 - 7 June 2001).

Abdul-Wahed, M.K., Al Heib, M., Senfaute, G. (2006), Mining-induced seismicity: Seismic measurement using multiplet approach and numerical modelling, INT J COAL GEOL 66 (12): $137-147$.

Aki, K., and Richards, P.G., Quantitative Seismology (W.H. Freemann, San Francisco 1980). 
Bennani, M., and Homand, F. (2004), Coverage formations at the level of areas in which there is a sudden collapse hazard, Géodéris R2004/002.

Boatwright, J., G.L., Choy and L.C.Seeking (2002), Regional Estimates of Radiated Seismic Energy, Bull. Seism.Soc.Am. 92, 1241-1255.

Brune, J. N. (1970), Tectonic stress and the spectra of seismic shear waves from earthquakes. J. Geophys. Res. 75(26), 4997-5009.

Contrucci, I., Klein, E., Bigarre, P., Lizeur, A., and Lomax, A., Early-warning microseismic systems applied to the management of post-mining large-scale ground failures: calibration by a geophysical field experimentof blast swarms (EGU, April 2008, Vienna, Geophys. Res. Abs., 10, EGU2008-A-09300, 2008).

Couffin, S., Bigarré, P., Bennani, M., Josien, J.P., Permanent real time microseismic monitoring of abandoned mines for public safety. Fields measurements in Geomechanics (ed. Myrvoll) (Sweets \& Zeitlinger, Lisse 2003) pp. 437-444.

Didier, C. (2008), The French Experience of Post Mining Management, Post Mining 2008, Nancy, France.

Driad-Lebeau, L., Lahaie, F., Al Heib, M., Josien, J.P., Bigarré, P., and Noirel, J.F. (2005), Seismic and geotechnical investigations following a rockburst in a complex French mining district, Int. J. Coal Geol., 64, (1-2), 66-78.

Finck, F., Kurz, J.H., Grosse, C.U., Reinhardt, H.W., (2003), Advances in Moment Tensor Inversion for Civil Engineering, in Non-Destructive Testing in Civil Engineering, International Symposium (NDT-CE 2003).

Geller, R.J., and Mueller, S. (1980), Four similar earthquakes in central California. Geophys. Res. Lett., 7(10):821-824.

Gibowicz, S. J., Young, R.P., Talebi, S.,and Lawrence, D.J., (1991), Source Parameters of Seismic 
Events at the Underground Research Laboratory in Manitoba, Canada: Scaling Relations for Events with Moment Magnitude Smaller than -2. Bull. Seismol. Soc. Am. 81(4), 1157-1182.

Gibowicz, S-J. (2006), Seismic doublets and multiplets at Polish coal and copper mines, Acta Geophysica, 54, 142-157, DOI 10.2478/s11600-006-0014-y.

Homand, F., \& Dagallier, G., (2004), Survey of the coverage formations of areas in which there is a non-negligible risk of sudden collapse, LAEGO, LG.FH.ARB.PSI.RPRE.03.0248.C.

Klein, E., Nadim, C., Bigarre, P., and Dunner, C., Global monitoring strategy applied to ground failure hazards (10th Int. Symposium on Landslides \& Engineering Slopes - Xi'an, Chine 2008.

Lees, J.M., 1998, Multiplet analysis at Coso geothermal, Bull. Seism. Soc. Am. 88, 1127-1143.

Li, T., Cai, M.F., Cai, M., (2007), A review of mining-induced seismicity in China, International Journal of Rock Mechanics and Mining Sciences, 44 (8), 1149-1171.

Lomax, A. and Snieder, R. (1995), Identifying sets of acceptable solutions to non-linear, geophysical inverse problems which have complicated misfit functions, Nonlinear processes in Geophys., v. 2, 3/4, 222-227.

Lomax, A. (2005), A reanalysis of the hypocentral location and related observations for the great 1906 California earthquake. Bull. Seism. Soc. Am., 91, 861-877.

Lomax, A., and Curtis, A., Fast, probabilistic earthquake location in 3D models using oct-tree importance sampling, European Geophysical Society (Nice 2001).

Lopes, B., (2002), Etude de l'environnement géologique du site de Tressange, BRGM/RP-51701-FR. Madariaga, R. (1976), Dynamics of an expanding circular fault. Bull. Seismol. Soc. Am., 66(3), 639-666. Magotra, N., Ahmed, N., and Chael, E. (1987), Seismic event detection and source location using single-station (three-component) data. Bull. Seismol. Soc. Am., 77(3), 958-971.

McGarr, A. (1992), An implosive component in the seismic moment tensor of a mining-induced tremor. Geophys. Res. Lett. 19(15), 1579-1582. 
Maubeuge P.L. (1955), Geological observations to the east of the Paris basin. Institut National Polytechnique de Lorraine, Vol. 1, pp. 70-300.

Miller, A., Richards, J. A, McCann, D.M., Browit, C.W.A., and Jackson, P.D. (1989). Microseismic techniques for monitoring incipient hazardous collapse conditions above abandoned mines, Quarterly Journal of Engineerin Geology, 22, 1-18.

Montagne, A., Tincelin, E., Astier, J., Varoquaux J.L. (1992). Les mines de fer de Lorraine. Chambre syndicale des mines de fer de France, Paris, p. 17; 43; 71-77; 243.

Moriya, H., Fujita, T., Niitsuma, H., Eisenblatter, J., Manthei, G., (2006), Analysis of fracture propagation behavior using hydraulically induced acoustic emissions in the Bernburg salt mine, Germany, International Journal of Rock Mechanics \& Mining Sciences, 43, 49-57.

Ogasawara, H., Fujimori, K., Koizumi, N., Hirano, N., Fujiwara, S., Otsuka, S., Nakao, S., Nishigami, K., Taniguchi, K., Iio, Y., Nishida, R., Oike, K., Tanaka, Y. (2002), Microseismicity induced by heavy rainfall around flooded vertical ore veins, PURE AND APPLIED GEOPHYSICS, 159 (1-3), 91-109.

Pinsky, V., Husen, S., Lomax, A. A comparative study of robust algorithms for rapid, automatic earthquake location (EGU, Vienna, April 2008) Geophys. Res. Abs., 10, EGU2008-A-07074, 2008.

Poupinet, G, Ellsworth, W. L., Frechet J. (1984). Monitoring velocity variations in the crust using earthquake doublets - an application to the calaveras fault, California. JOURNAL OF GEOPHYSICAL RESEARCH, 89(NB7) 5719-5731.

Rubin, A.M., Gillard, D. and Got, J.L. (1999). Streaks of microearthquakes along creeping faults. Nature, 400:635-641.

Schaff, D.P., Bokelmann, G.H.R., Beroza, G.C., Waldhauser, F. and Ellsworth, W.L. (2002), Highresolution image of Calaveras Fault seismicity. J. Geophys. Res., 107(B7):2186, doi: 
10.1029/2001JB000633.

Samson, J. C. (1983), The spectral matrix, eigenvalues, and principal components in the analysis of multichannel geophysical data, Annales Geophysicae, 1(2), 115-119.

Senfaute, G., Chambon, C., Bigarré, P. (1997) Spatial distribution of mining tremors and the relationship to rockburst hazard, Pure Appl. Geophys. 150 (3-4): 451-459.

Senfaute, G., Abdul-Wahed M.K., Piguet, J.P., Josien, J.P., Qualification of the microseismic monitoring technique applied to the risk of collapse or iron mines (Eurock 2000, Aachen 2000) pp. 597-602.

Sileny, J., and Milev, A. (2006). Seismic Moment Tensor Resolution on a Local Scale: Simulated Rockburst and Mine-induced Seismic Events in the Kopanang Gold Mine, South Africa, Pure Appl. Geophys., 163, 1495-1513.

Slunga, R., Rognvaldsson, S.T., Bodvarsson, R. (1995), Absolute and relative locations of similar events with applisation to microearthquakes in southern Iceland. Geophysical Journal International, 123 (2), 409-419.

Tarantola, A. and Valette, B. (1982). Generalized Nonlinear Inverse Problems Solved using the Least Squares Criterion. Reviews of Geophysics and Space Physics, 20(2), 219-232.

Tastet, J., Contrucci, I., Klein, E., Bigarré, P., and Driad-Lebeau, L. (2007), Large-scale field experiment to calibrate microseismic source parameters applied to real-time monitoring of post-mining instabilities, Proceedings of the 11th congress of the international society for rock mechanics, 9-13 july 2007, Lisbon, Portugal. Leiden, The Netherlands : Taylor \& Francis, Vol. 2, 1147-1150.

Trifu, C., and Shumila, V. (2002), The use of uniaxial recordings in moment tensor inversions for induced seismic sources, Tectonophysics 356, 171-180.

Urbancic, T.I. and Young R.P. (1993), Space-time variations in source parameters of mining-induced 
seismic events with $\mathrm{M}<0$, Bull.Seism.Soc.Am. 83(2): 378 - 397.

Volker, O. and Roth, M. (2003), Automated seismic event location for hydrocarbon reservoir. Computers \& Geosciences, 29, 851-863.

Waldhauser, F. and Ellsworth, W.L. (2000), A double-difference earthquake location algorithm: Method and application to the Northern Hayward Fault. Bull. Seismol. Soc. Am., 90(6): 13531368.

Yamada, T., Mori, J.J., Ide, S., Abercrombie, R.E., Kawakata, H., Nakatani, M., Iio, Y., Ogasawara, H. (2007), Stress drops and radiated seismic energies of microearthquakes in a South African gold mine. Journal of Geophysical Research, Vol.112, DOI: 10.1029/2006JB004553. 


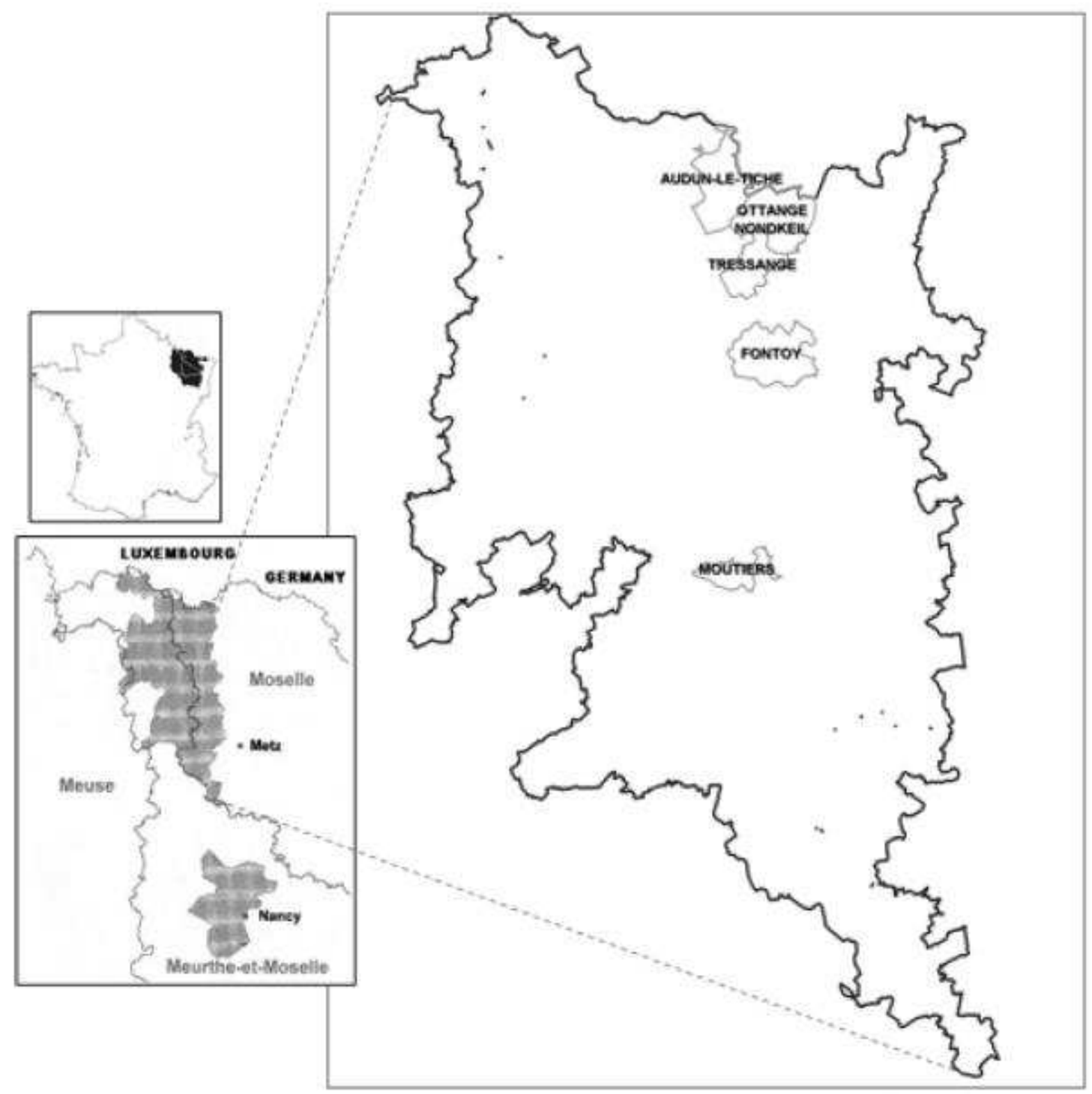

Figure 1: location map of the monitored areas and experimental sites. 


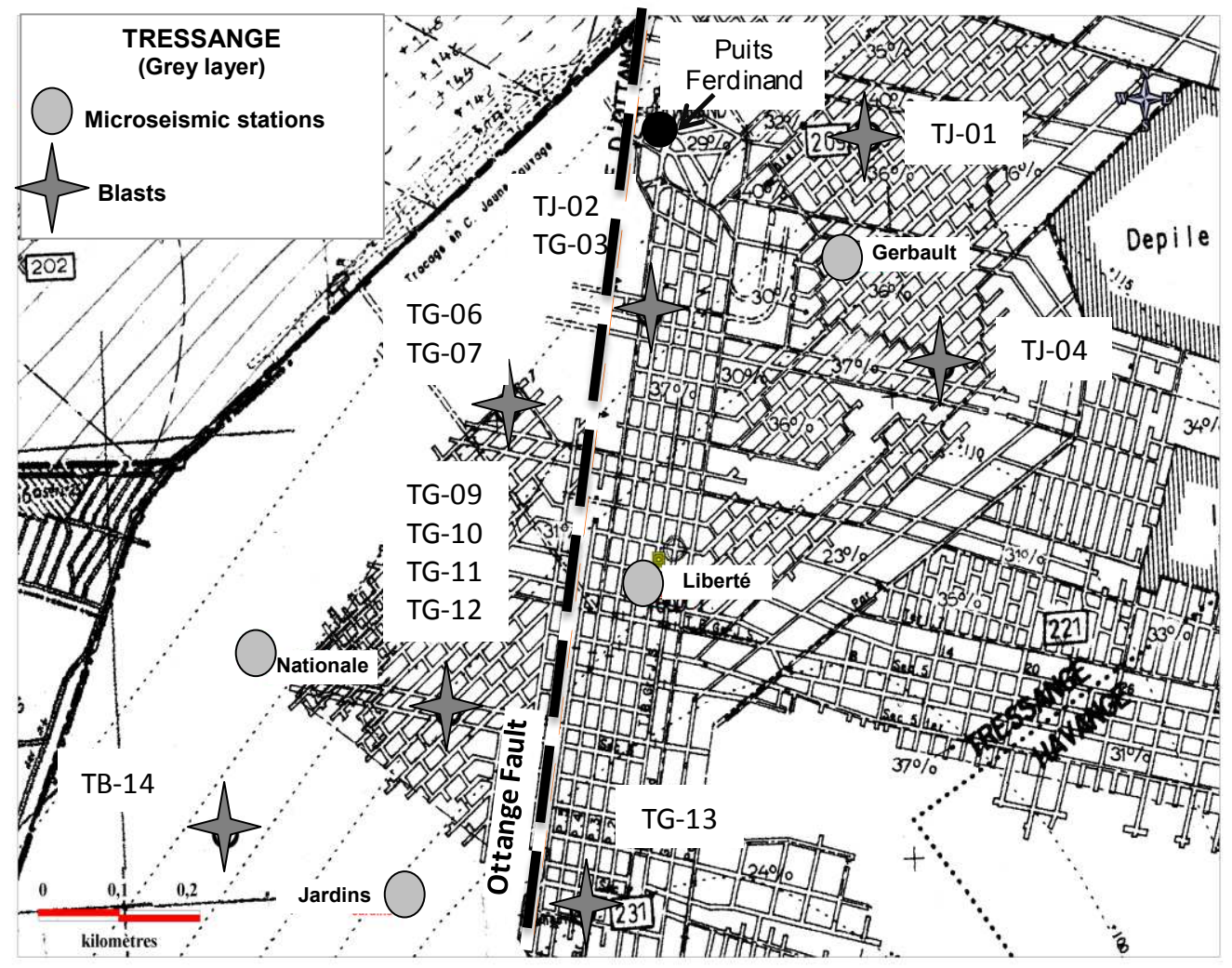

Figure 2: Mining map of the Tressange site. Grey spots represent the microseismic stations; Dark crosses represent the blasts; the Ottange Fault is in thick dotted line. 
a)

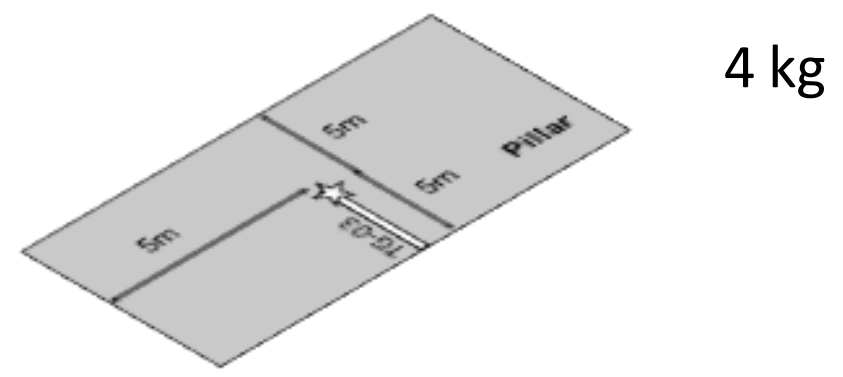

b)

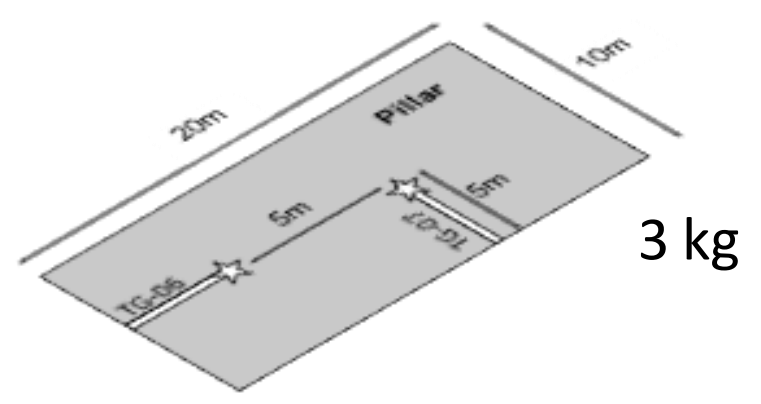

c)

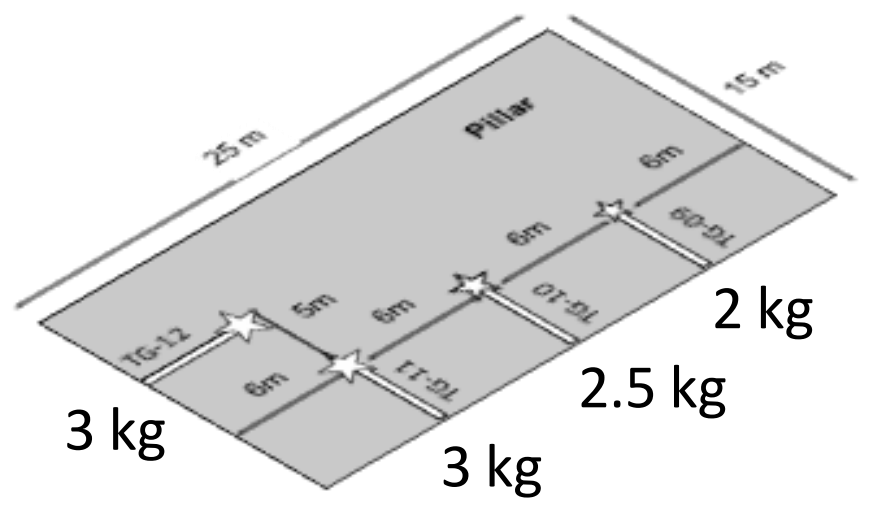

Figure 3: configuration of a) a source blast, b) an orientation blast, c) a multiplet blast. 


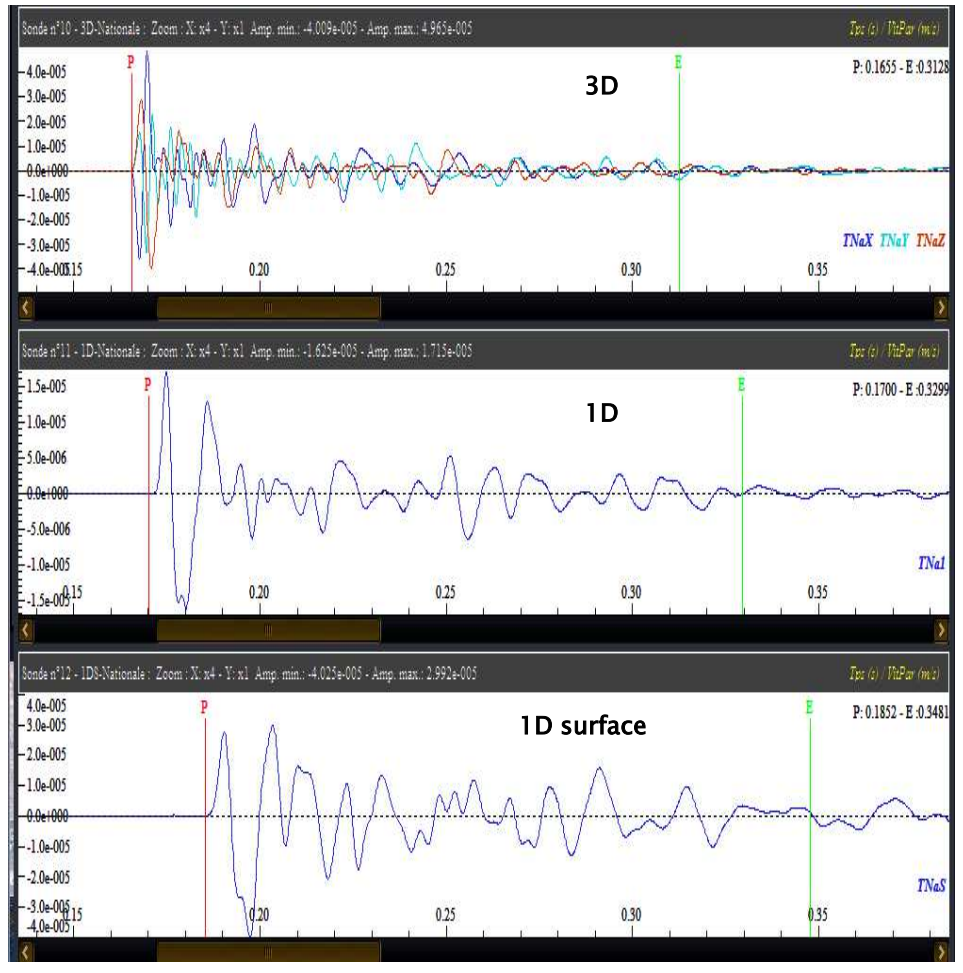

Figure 4 : Seismograms of blast number 9 recorded by the microseismic station "Nationale" of the Tressange network (amplitude in $\mathrm{mm} / \mathrm{s}$ versus time in s). The 3D probe is the deepest one, the 1D surface probe is the shallowest one. 


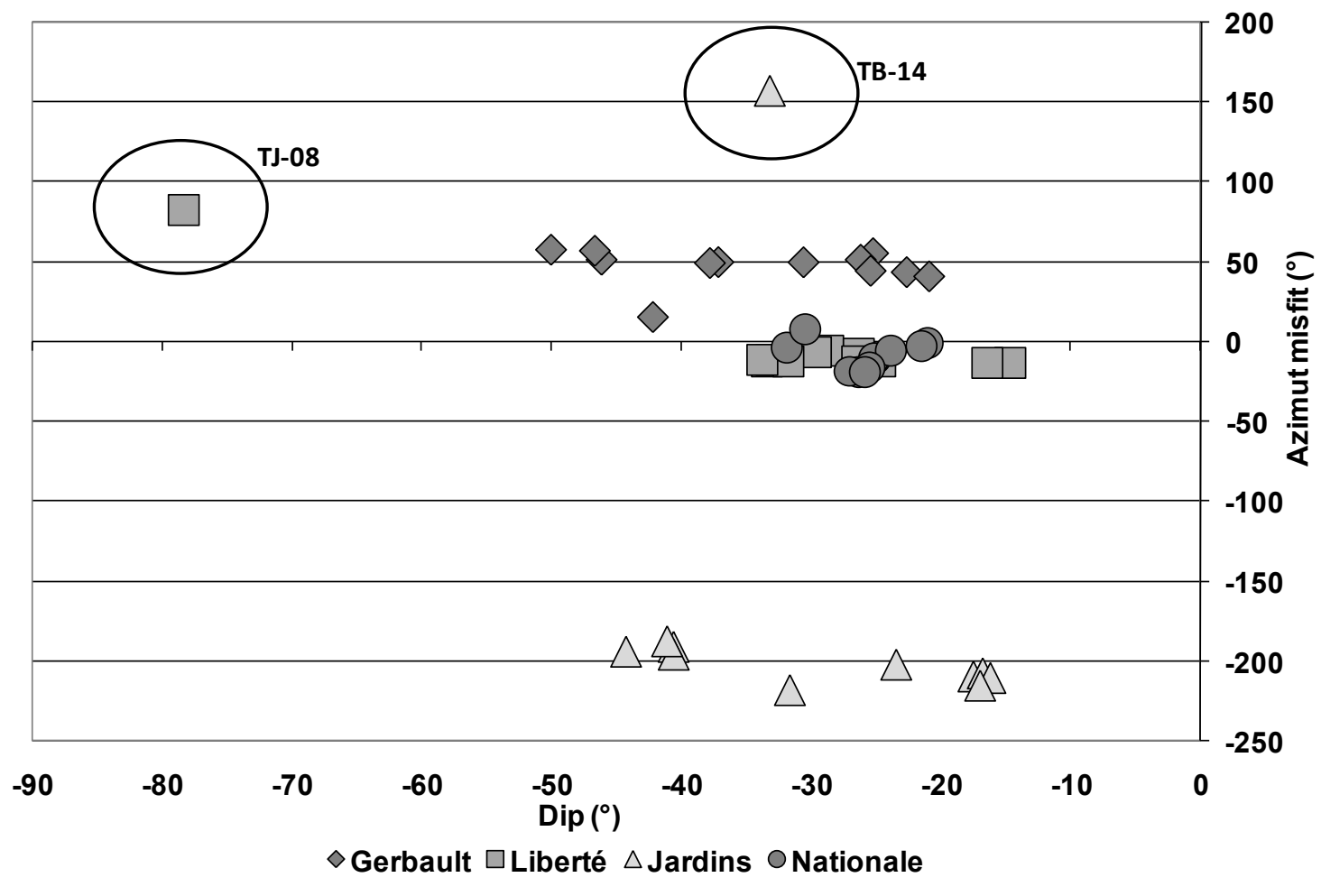

Figure 5: Azimuth error versus dip for the 3D microseismic probes of Tressange network. 


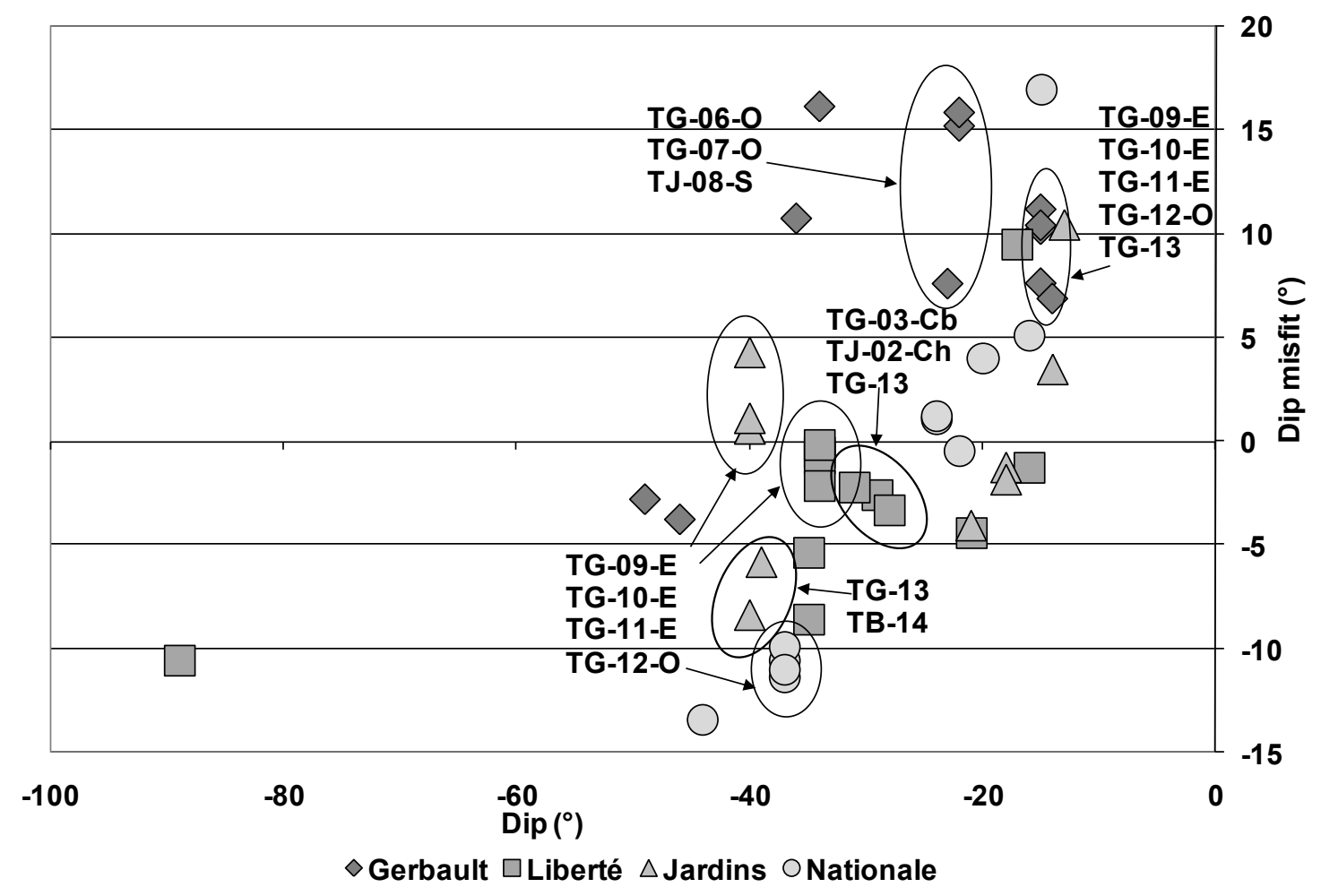

Figure 6: dip misfit versus measured dip for the 3D microseismic sensors of Tressange network. 
a)

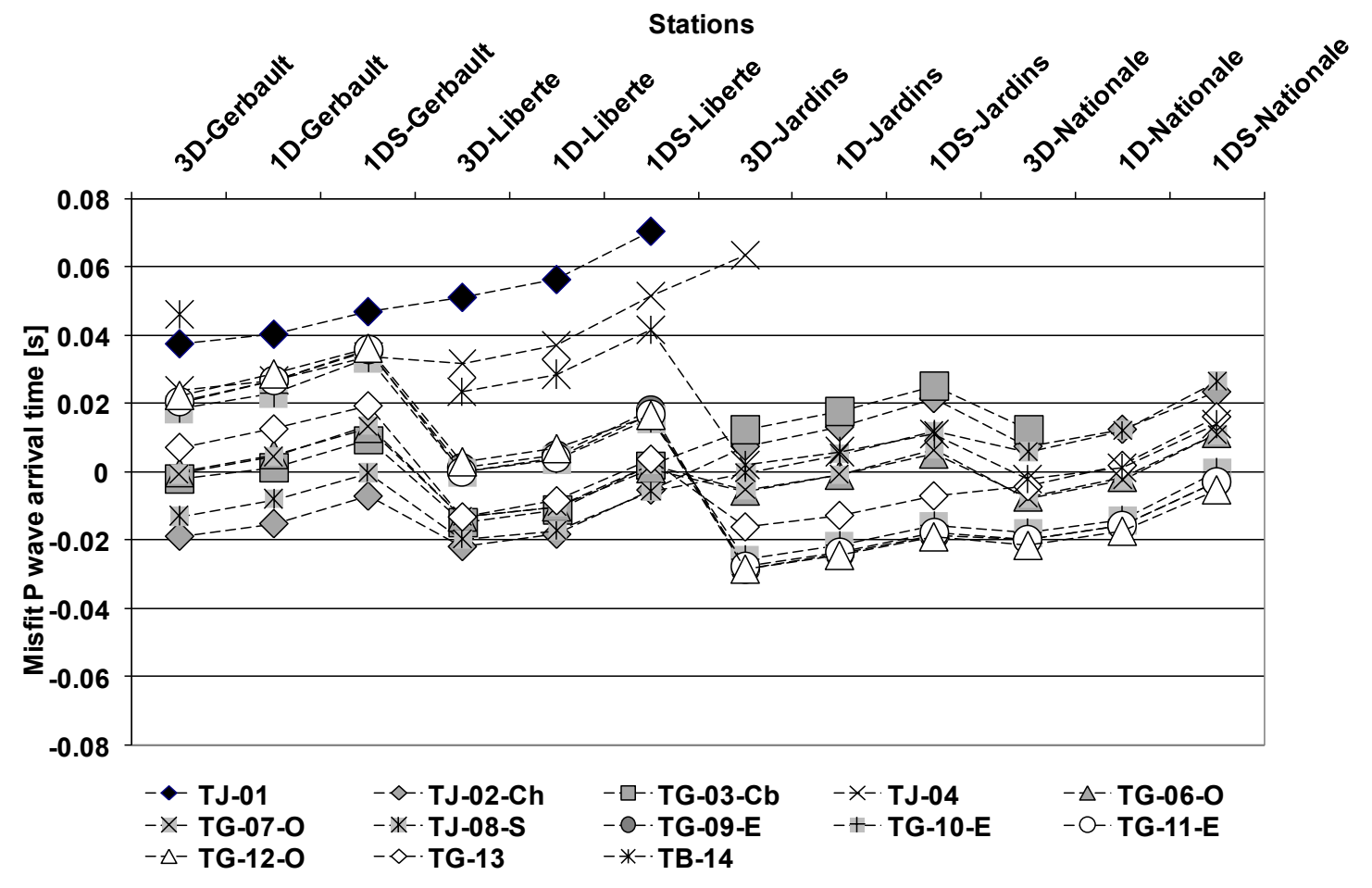

b)

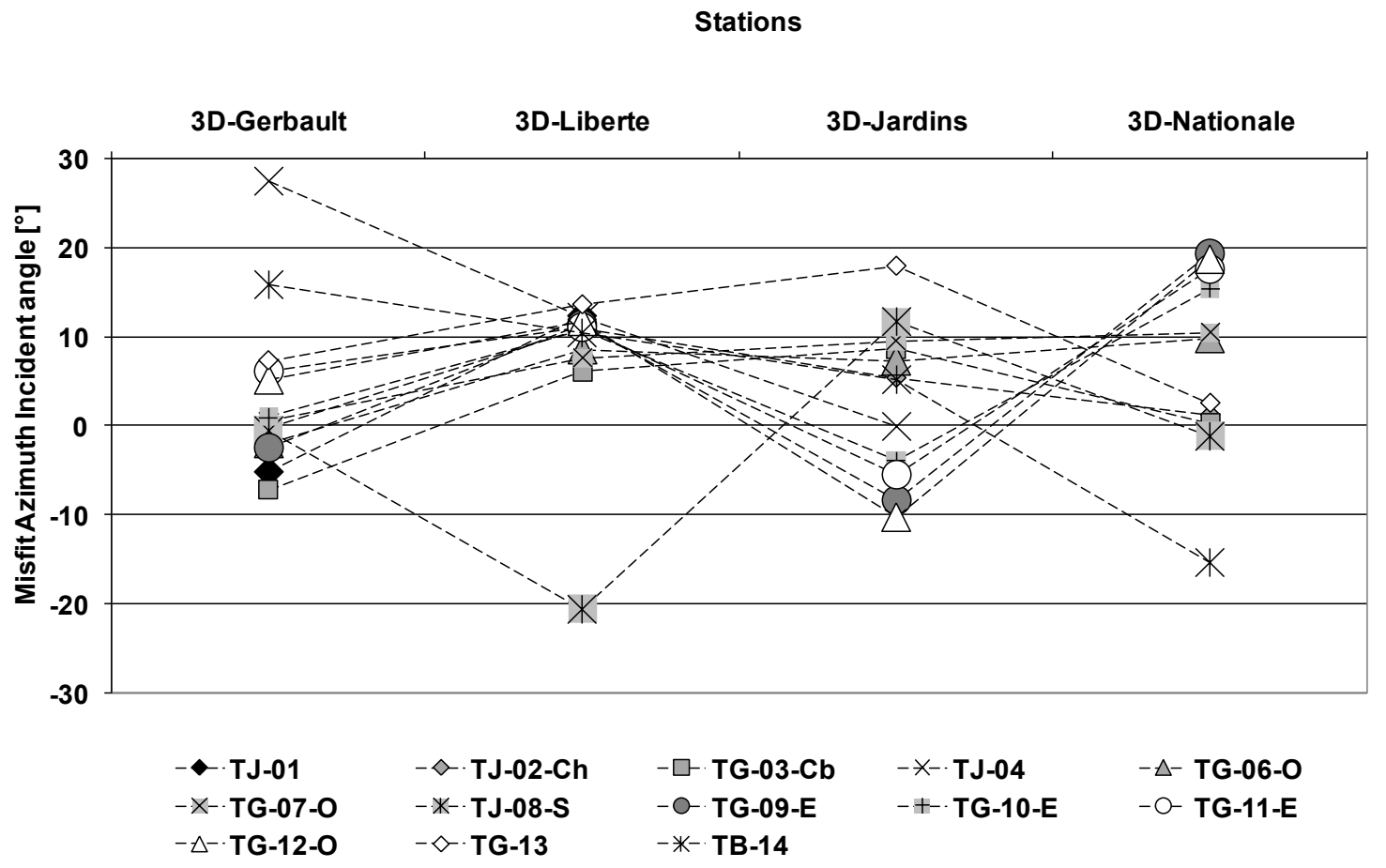


c)

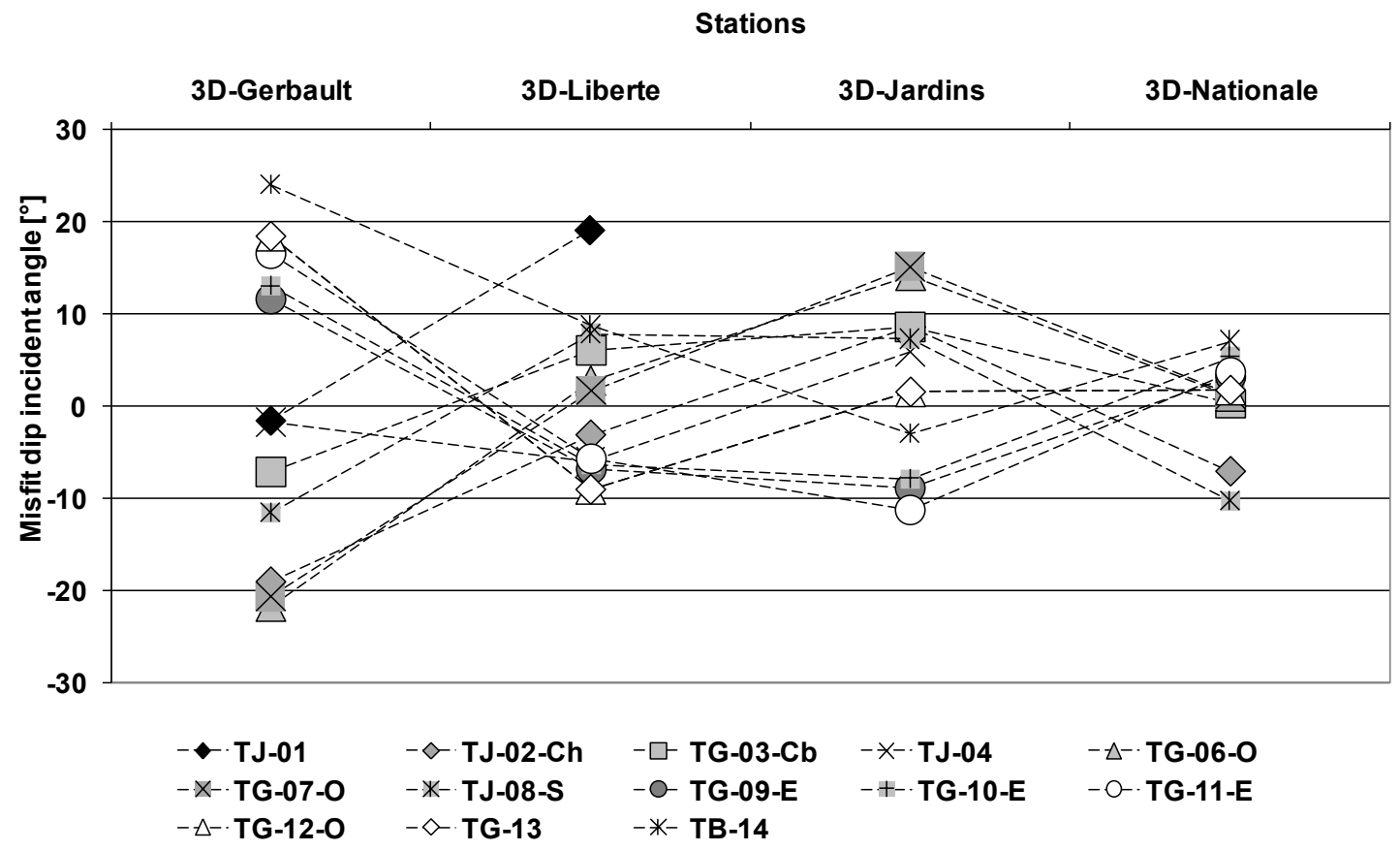

Figure 7: step 1, inversion of all the data for calculating the velocity model. Differences between calculated and measured values for all the blasts on the Tressange site of (a) the arrival times of $\mathrm{P}$ waves, (b) azimuths and (c) dips. 
a)

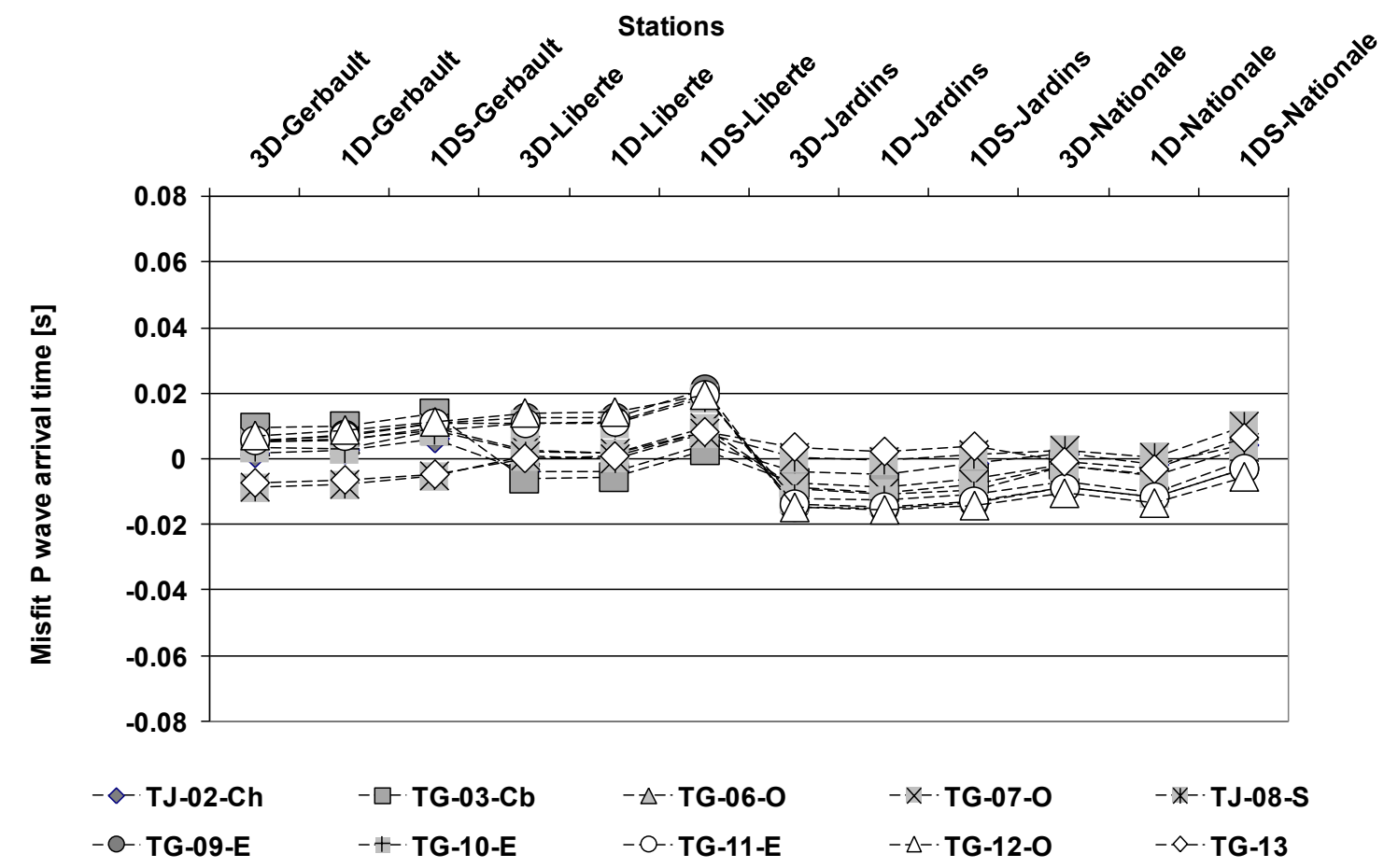

b)

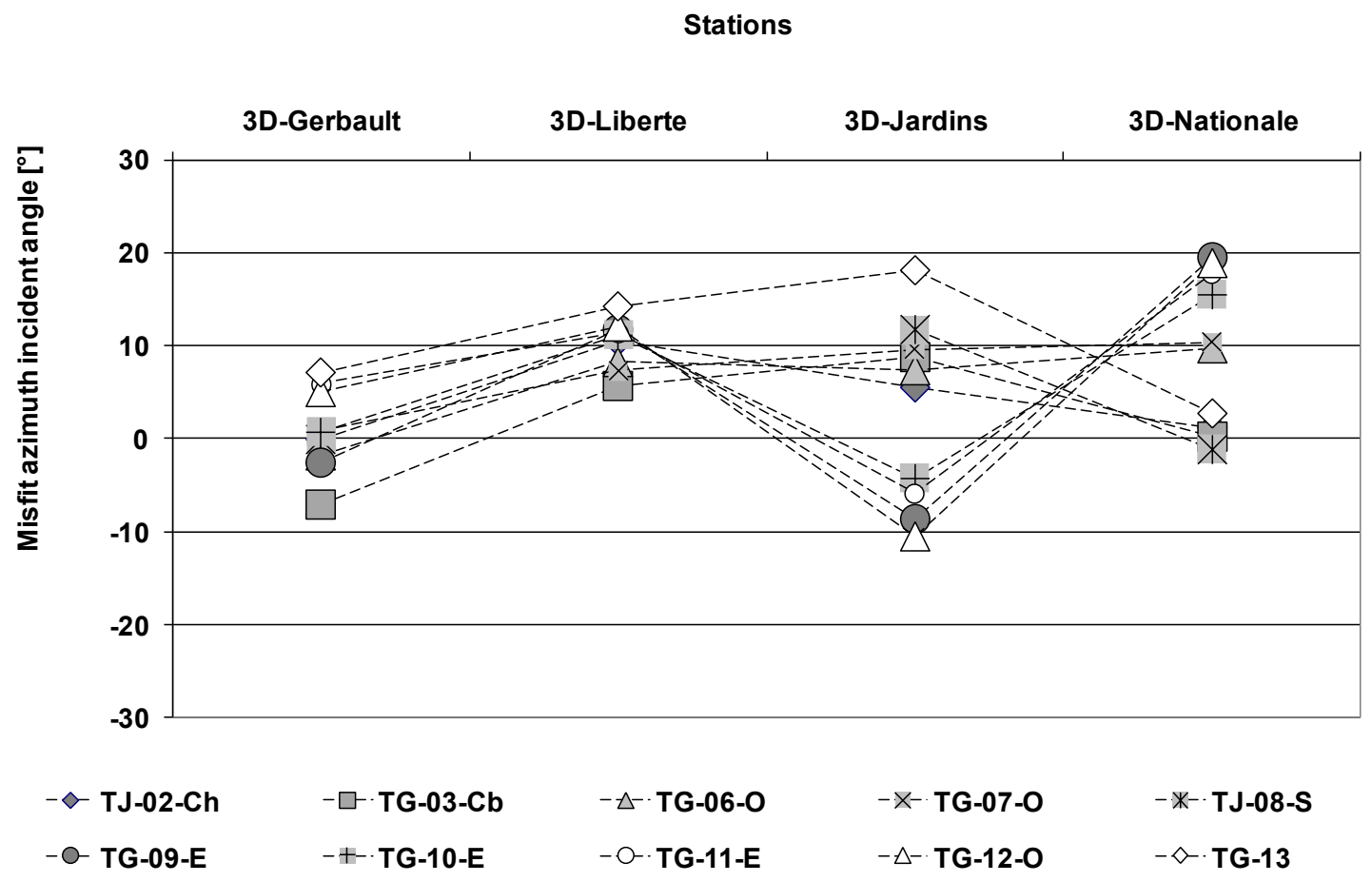


c)

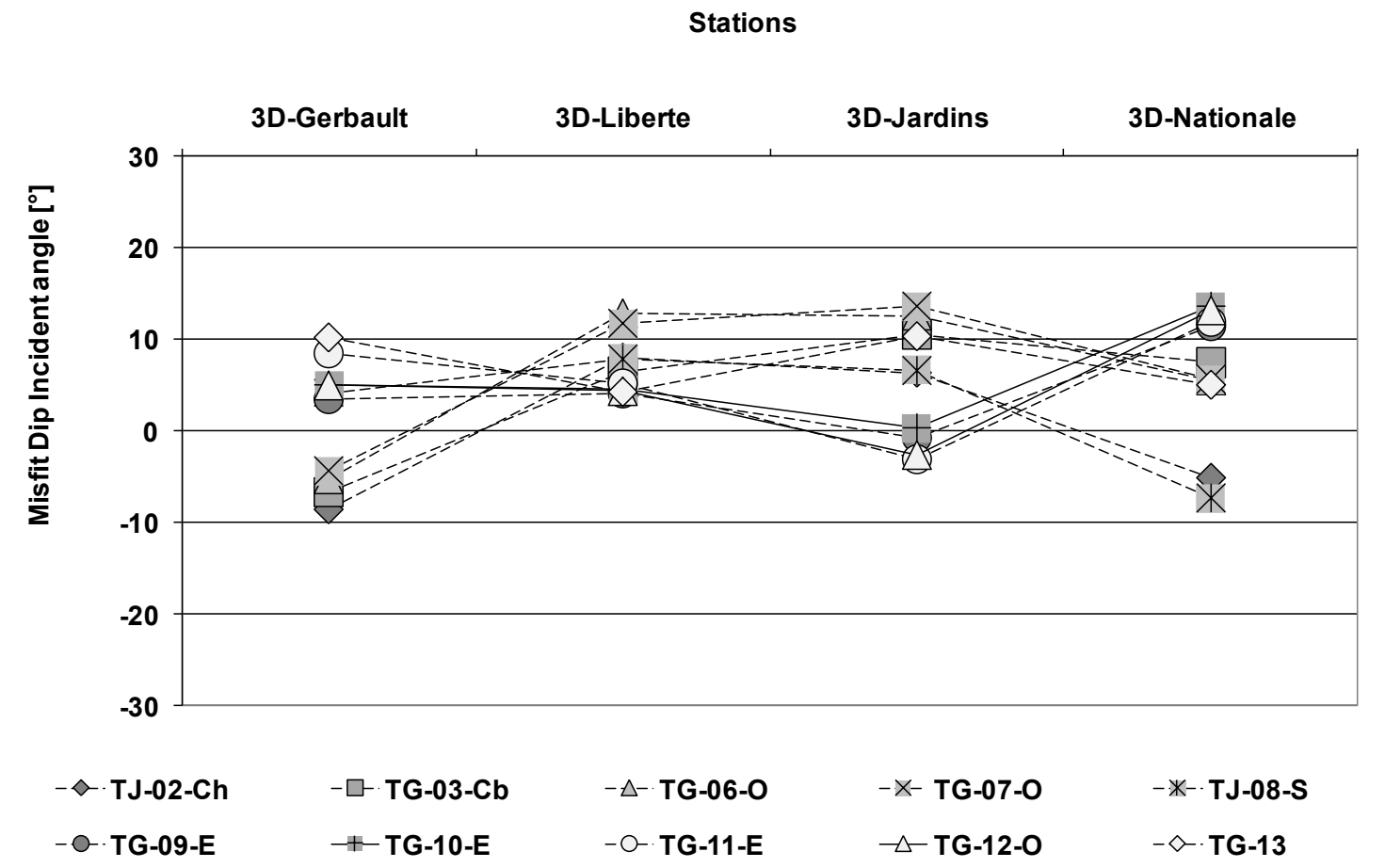

Figure 8: step 2, inversion without abnormal data for the calculation of the velocity model. Differences between calculated and measured values for all blasts on the Tressange site of (a) the P wave arrival times, (b) azimuths and (c) dips 


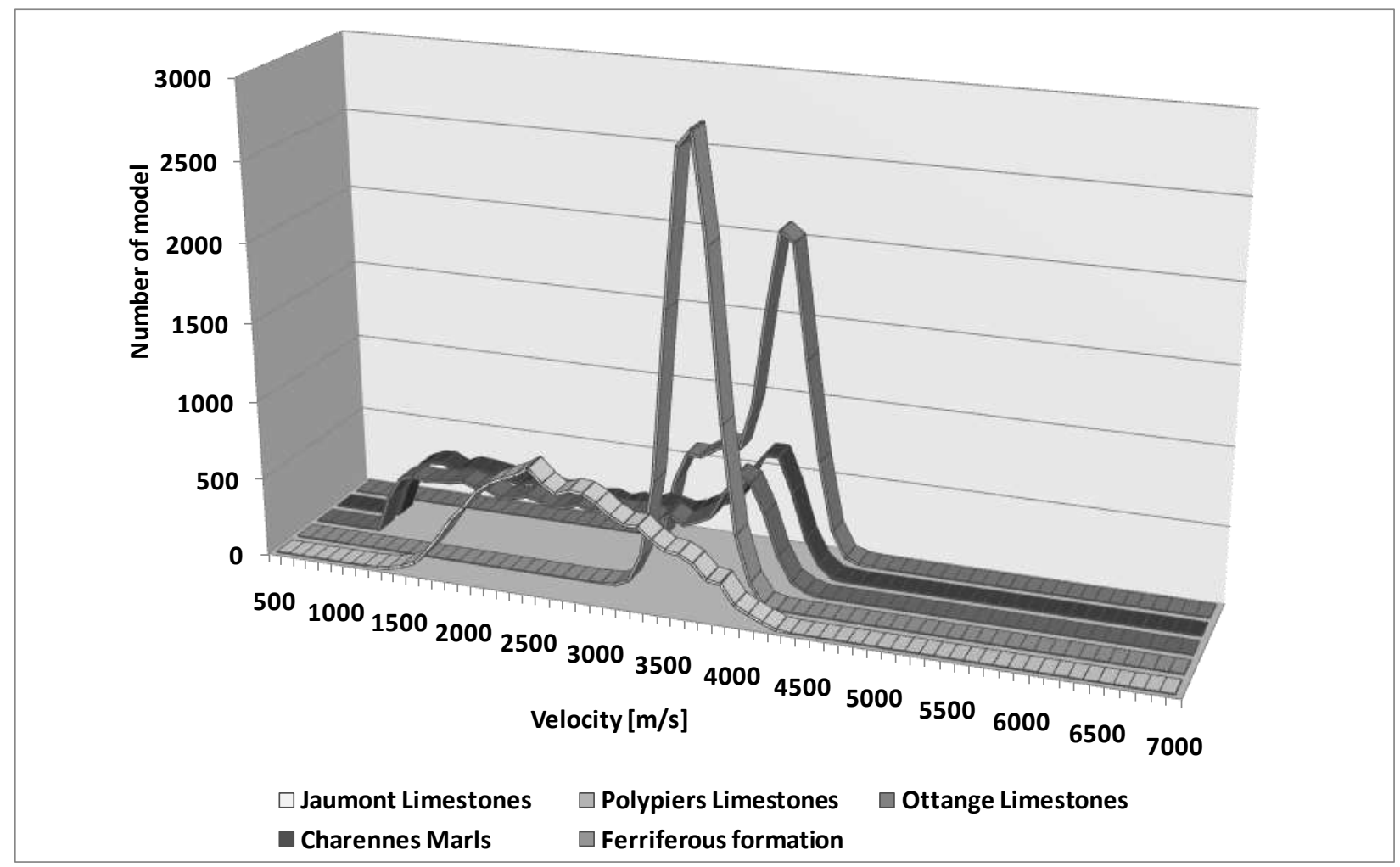

Figure 9: distribution of the velocities tested by inversion for each of the geological layers considered. 
a)

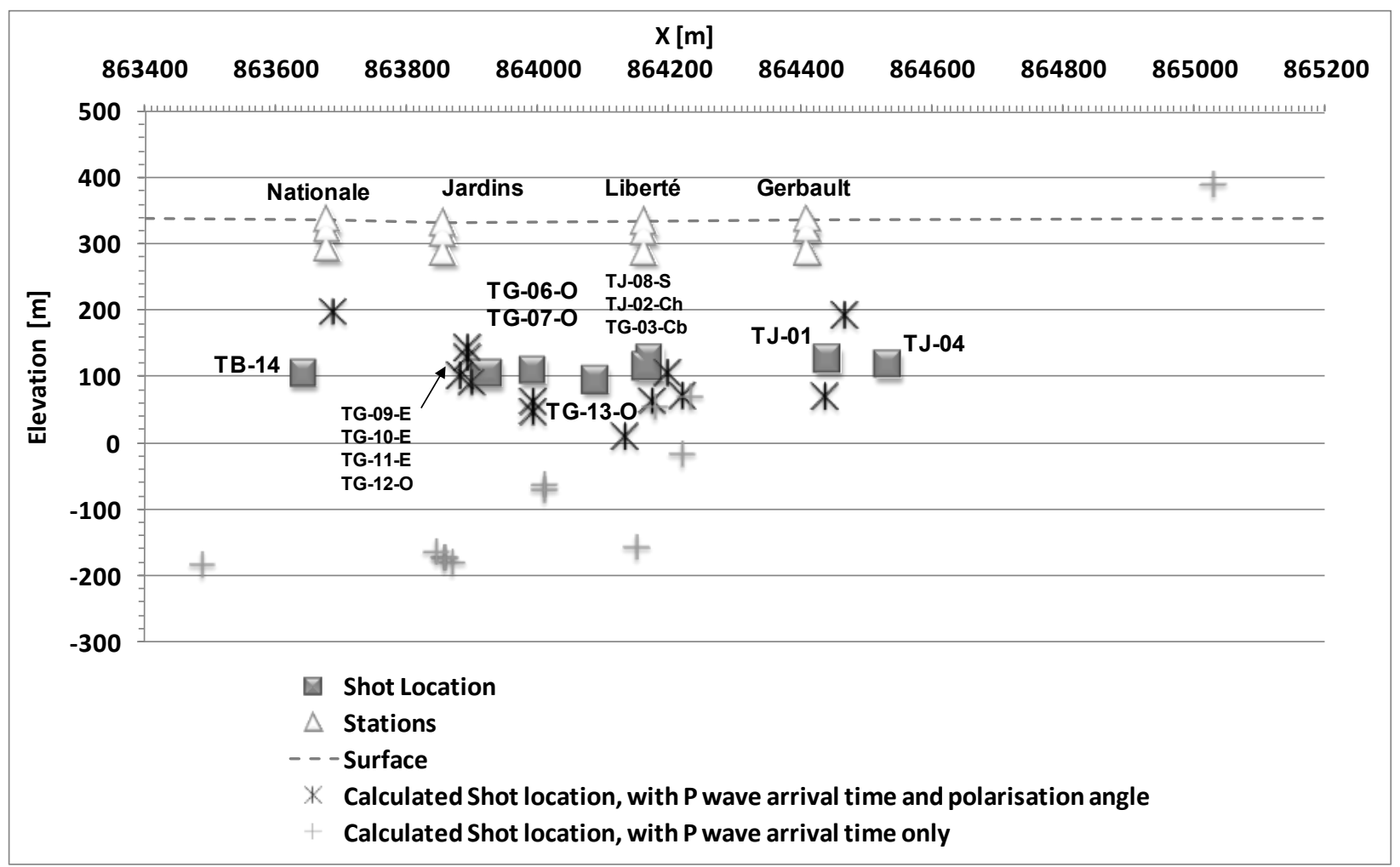

b) 


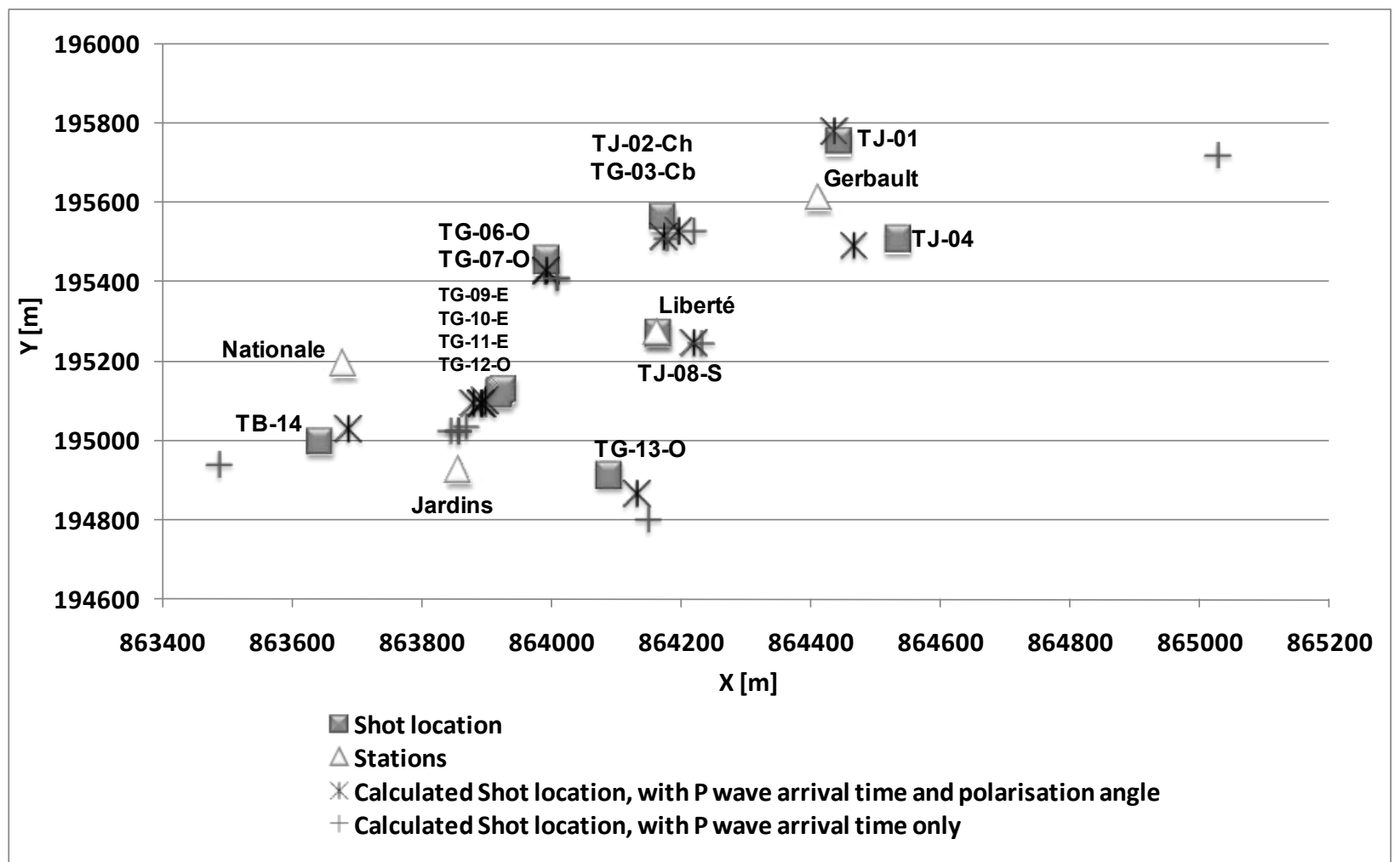

Figure 10: relocation of Tressange calibration blasts, representation of the actual relocated positions (a) cross-sectional view and (b) plan view. 
a)

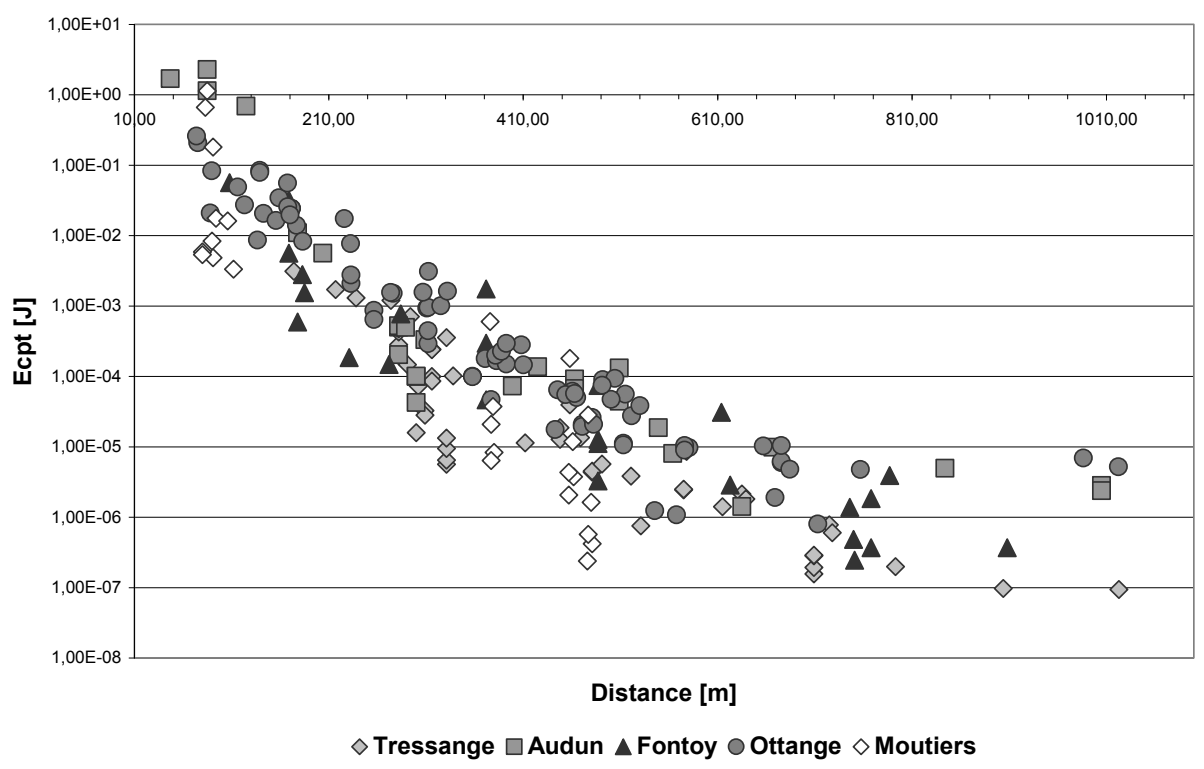

b)

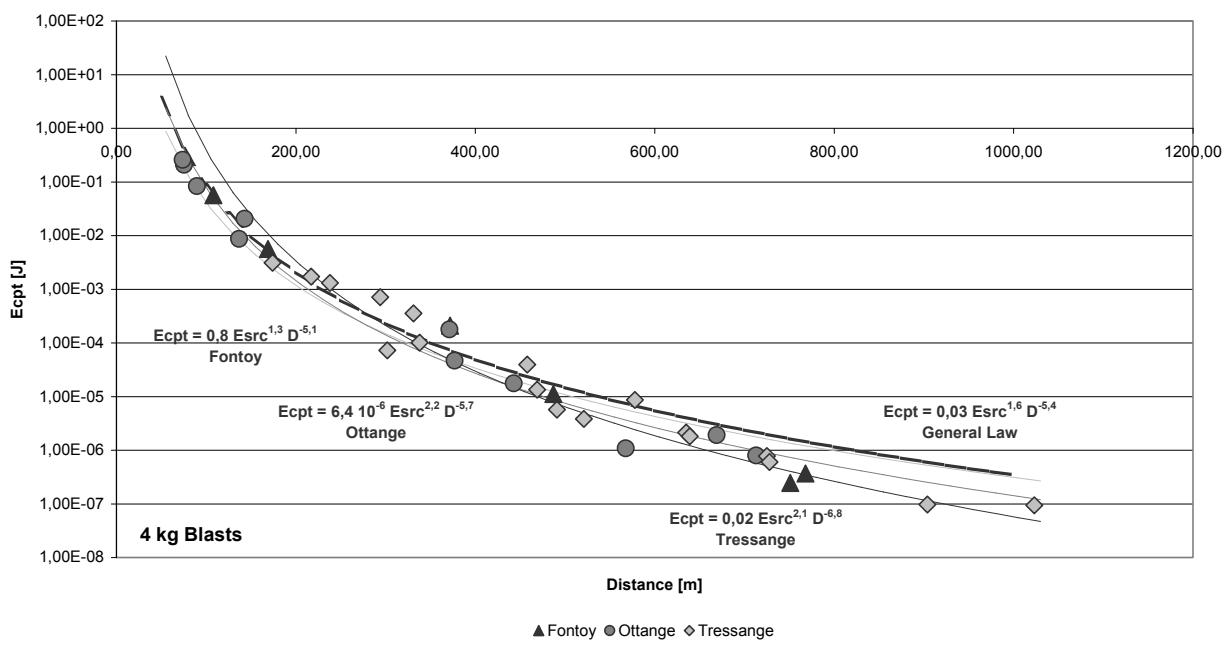

Figure 11: a) figure of the energy recorded at the 3D sensor as a function of the distance for all experimental sites and all blast explosive charge. b) graphic comparison of function for a constant source energy term corresponding to $4 \mathrm{~kg}$ of explosive on three different sites (Fontoy, Ottange and Tressange), i.e. 11 stations and 11 blasts. 